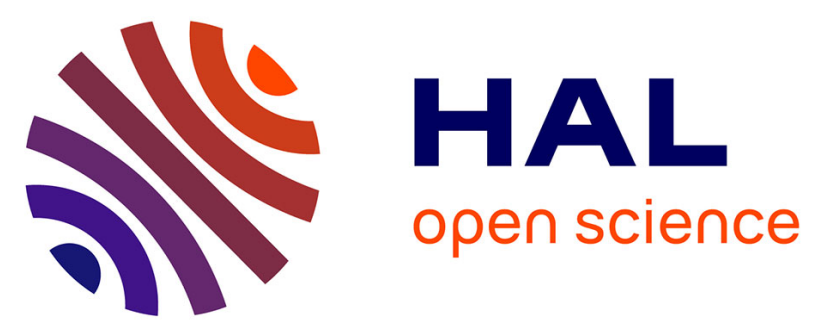

\title{
Role of Chemical Dynamics Simulations in Mass Spectrometry Studies of Collision-Induced Dissociation and Collisions of Biological Ions with Organic Surfaces
}

Ana Martin Somer, Veronica Macaluso, George Barnes, Li Yang, Subha Pratihar, Kihyung Song, William L. Hase, Riccardo Spezia

\section{To cite this version:}

Ana Martin Somer, Veronica Macaluso, George Barnes, Li Yang, Subha Pratihar, et al.. Role of Chemical Dynamics Simulations in Mass Spectrometry Studies of Collision-Induced Dissociation and Collisions of Biological Ions with Organic Surfaces. Journal of The American Society for Mass Spectrometry, 2019, 31 (1), pp.2-24. 10.1021/jasms.9b00062 . hal-02565786

\author{
HAL Id: hal-02565786 \\ https://hal.science/hal-02565786
}

Submitted on 17 Nov 2020

HAL is a multi-disciplinary open access archive for the deposit and dissemination of scientific research documents, whether they are published or not. The documents may come from teaching and research institutions in France or abroad, or from public or private research centers.
L'archive ouverte pluridisciplinaire HAL, est destinée au dépôt et à la diffusion de documents scientifiques de niveau recherche, publiés ou non, émanant des établissements d'enseignement et de recherche français ou étrangers, des laboratoires publics ou privés. 


\title{
Role of Chemical Dynamics Simulations in Mass Spectrometry Studies of Collision-Induced Dissociation and Collisions of Biological Ions with Organic Surfaces
}

\author{
Ana Martin Somer, ${ }^{\text {a } V e r o n i c a ~ M a c a l u s o, ~}{ }^{b}$ George L. Barnes, ${ }^{c}$ Li Yang, ${ }^{d}$ \\ Subha Pratihar, ${ }^{\mathrm{e}}$ Kihyung Song, ${ }^{\mathrm{f}}$ William L. Hase, ${ }^{\mathrm{e}, *}$ and Riccardo Spezia ${ }^{\mathrm{g}, *}$ \\ ${ }^{a}$ Departamento de Química, Facultad de Ciencias, Módulo 13 \\ Universidad Autónoma de Madrid, Campus de Excelencia UAM-CSIC \\ Cantoblanco, 28049 Madrid, Spain \\ ${ }^{\mathrm{b}}$ LAMBE, Univ Evry, CNRS, CEA, Université Paris-Saclay, 91025 Evry, France \\ ${ }^{\mathrm{c}}$ Siena College \\ Department of Chemistry and Biochemistry \\ Siena College, Loudonville, NY 12211, United States of America \\ ${ }^{\mathrm{d}}$ MIIT Key Laboratory of Critical Materials Technology for New Energy Conversion and \\ Storage, \\ School of Chemistry and Chemical Engineering \\ Harbin Institute of Technology \\ Harbin 150001, P. R.China \\ ${ }^{\mathrm{e}}$ Department of Chemistry and Biochemistry \\ Texas Tech University, Lubbock, Texas 79409, United States of America \\ ${ }^{f}$ Department of Chemistry, Korea National University of Education, Chungbuk, Republic of \\ Korea \\ gSorbonne Université, CNRS, Laboratoire de Chimie Théorique, \\ LCT, 4, Place Jussieu, 75252 Paris Cedex 05 (France).
}

Correspondence to: bill.hase@ttu.edu ; riccardo.spezia@sorbonne-universite.fr 


\begin{abstract}
In this article, a perspective is given of chemical dynamics simulations of collisions of biological ions with surfaces and of collision-induced dissociation (CID) of ions. The simulations provide an atomic-level understanding of the collisions and, overall, are in quite good agreement with experiment. An integral component of ion/surface collisions is energy transfer to the internal degrees of freedom of both the ion and the surface. The simulations reveal how this energy transfer depends on the collision energy, incident angle, biological ion, and surface. With energy transfer to the ion's vibration fragmentation may occur, i.e. surface-induced dissociation (SID), and the simulations discovered a new fragmentation mechanism, called shattering, for which the ion fragments as it collides with the surface. The simulations also provide insight into the atomistic dynamics of soft-landing and reactive-landing of ions on surfaces. The CID simulations compared activation by multiple "soft" collisions, resulting in random excitation, versus high energy single collisions and non-random excitation. These two activation methods may result in different fragment ions. Simulations provide fragmentation products in agreement with experiments, and hence can provide additional information regarding the reaction mechanisms taking place in experiment. Such studies paved the way on using simulations as an independent and predictive tool in increasing fundamental understanding of CID and related processes.
\end{abstract}

Keywords: Surface Induced Dissociation; Collision Induced Dissociation; Chemical Dynamics Simulations; Theoretical Modeling 


\section{Introduction}

The study of biological ions fragmentation is an important component of mass spectrometry. ${ }^{1-10}$ In this perspective article, collisions of these ions with surfaces ${ }^{1-6}$ and their gasphase collision-induced dissociation $(\mathrm{CID})^{7-10}$ are considered. Ions with a broad range of mass and charge may be prepared by electrospray ionization (ESI). ${ }^{11}$ The resulting fragmentation products, in CID or with a surface (surface-induced dissociation, $\operatorname{SID}^{12,13}$ ), can provide additional information regarding the biological molecules under analysis. This review will highlight important advances that can now be obtained from simulations of such processes.

In SID, a specific ion is selected, given a fixed translational energy, and collided with a surface. When sufficient translational energy is imparted to the ion, it may fragment and provide information regarding the ion's dissociation energetics and mechanisms, as well as a fingerprint of the ion's primary structure. In addition to SID, the ion may be deposited on the surface by physisorption, soft-landing (SL), ${ }^{14,15}$ or chemisorption, reactive landing (RL), ${ }^{16}$ these are hyperthermal processes in contrast to thermal physisorption and chemisorption. When a molecule sticks to a surface, it can bind with either chemical interactions (chemisorption) or physical interactions (physisorption). Chemisorption involves the formation of a chemical bond between the adsorbate and surface. ${ }^{17}$ Physisorption has weaker interactions, involving dispersion and electrostatic forces. For SL the ion desorbs intact from the surface ${ }^{15}$ and is physisorption, while for RL the ion is chemically bound to the surface and is chemisorption. SL and RL interface nicely with traditional surface science experiments of non-thermal gas-surface collisions leading to physisorption and chemisorption. ${ }^{18-23}$ The chemisorption probability has been investigated versus both the projectile's collision energy ${ }^{18,19}$ and vibrational energy. ${ }^{19}$ Physisorption has been studied experimentally for both translationally ${ }^{20-22}$ and vibrationally ${ }^{23}$ excited projectiles, and in chemical dynamics simulations versus translational energy. ${ }^{24,25}$

SL and RL have important applications including purification of compounds from complex mixtures, ${ }^{26-28}$ preparation of protein or peptide microarrays, ${ }^{29}$ development of biocompatible substrates and biosensors, ${ }^{30,31}$ deposition of mass-selected cluster ions, ${ }^{32-34}$ and preparation of novel synthetic materials, ${ }^{35,36}$ including nanomaterials. ${ }^{37,38}$ Understanding the molecular basis of $\mathrm{SL}$ and RL is thus crucial to further advances of such techniques. 
In CID, ions collide with an inert gas, such as $\mathrm{N}_{2}$ or a noble gas (Ar, Ne, $\mathrm{Xe}$ ), and as in SID provide a fragmentation pattern giving information regarding the primary structure of the ion. One important application of CID is in characterization of polypeptides, whose different types of fragments have a specific nomenclature. ${ }^{39}$ In peptide CID, several studies were performed to understand fragmentation products and related mechanisms. ${ }^{9,40-45}$ In CID there is a large number of different instruments (details can be found in dedicated literature ${ }^{46}$ ) with specific characteristics which can influence product distribution. In particular, differences in the ion formation method, as well as the way the ion is controlled in the instrument and activated by collision with the inert gas may largely affect the types and the relative abundance of products. Obtaining direct experimental insight into the fragmentation mechanism ${ }^{47-52}$ is possible by studying the reactants and fragments via Infra-Red Multiple Photon Dissociation (IRMPD) spectroscopy. ${ }^{53}$ Such fundamental studies on CID fragmentation mechanisms were also done on other biological molecules, like nucleic acids $^{54-58}$ and carbohydrates. ${ }^{59-65}$ Applications of CID are found in many fields like proteomics, ${ }^{66-}$ ${ }^{68}$ metabolomics, ${ }^{69}$ forensic sciences, ${ }^{70}$ and analysis and detection of doping substances. ${ }^{71}$ Understanding the molecular mechanisms of CID is a key step to predict fragmentations independently from experiments. Chemical dynamics simulations can help at this aim, since it is possible (as we will detail in the present article) to use them to let the ions fragment by modeling the CID conditions. These simulations are able to predict fragmentation products as well as corresponding reaction mechanisms: they can now be used not only to understand experimental spectra but also to predict fragmentation mechanisms of new structures, like e.g. different isomers with the same chemical formula.

Chemical dynamics simulations of SID, SL, RL, and CID are reviewed in the following. An important component of the simulations is to compare with experiment to confirm the accuracy of the simulations and assist in interpreting experimental spectra. The simulations provide atomistic detail concerning the dynamics of SID, SL, RL, and CID processes, which is difficult to obtain from typical experiments.

\section{Collisions of Biological Ions with Organic Surfaces}

In recent work, ${ }^{72,73}$ a review and perspective were published which address chemical dynamics simulations of collisions of biological ions with surfaces. A motivating factor for these simulations was the finding that chemical dynamics simulations ${ }^{74-77}$ for $\mathrm{SiMe}_{3}{ }^{+}$and $\mathrm{Cr}^{+}(\mathrm{CO})_{6}$ give 
collisional energy transfer probabilities in agreement with experiment. ${ }^{78-80}$ Here, theoretical methods for the chemical dynamics simulations, the simulation results, and the impact of the simulations on experiments are discussed. In the following, four aspects of the dynamics associated with collision of biological ions with organic surfaces are discussed. The first is the efficiency of energy transfer from the collision's translational energy to the ion's internal degrees of freedom and to the surface, upon collision with the surface. These are important for modeling $\operatorname{SID}^{12,13}$ of the ion. The second addresses fundamental dynamics for SID fragmentation. For the third, softlanding (SL) ${ }^{14,15}$ of the ion is considered, where the ion physisorbs intact on the surface without fragmenting or reacting. The fourth is reactive-landing (RL), ${ }^{16}$ collisions in which the ion reacts with the surface and chemisorbs. SL and RL are processes for preparing materials with a broad range of technological applications. However, before these four features of biological ion + organic surface collisions are discussed, the methodology for the chemical dynamics simulations is first outlined.

\section{A. Simulation methodology}

Chemical dynamics simulations involve calculating ensembles of classical trajectories to represent experiments. Two important components of the simulations are the potential energy function and the method for calculating the classical trajectories. Each is described below.

\section{A.1. Models for potential energy function}

The potential energy function for the ion/surface is represented as

$$
V_{\text {total }}=V_{\text {ion }}+V_{\text {surface }}+V_{\text {ion-surface }}
$$

where $V_{\text {ion }}$ is the biological ion's intramolecular potential, $V_{\text {surface }}$ is the surface's potential, and $V_{\text {ion-surface }}$ is the intermolecular potential between the ion and surface. Two models have been used for $V_{i o n}$. The first model uses the AMBER molecular mechanics (MM) force field,${ }^{81}$ which allows the ion to vibrate and absorb energy, but to not fragment. The second model obtains the ion's potential directly from a quantum mechanical (QM) electronic structure theory such as AM1 or MP2 ${ }^{82,83}$ resulting in a simulation referred to as $\mathrm{QM}+\mathrm{MM}$ direct dynamics. ${ }^{84}$ With this model, fragmentation of the ion may be studied.

Accurate MM potentials were used for $V_{\text {surface }}$. The MM potential developed by Mar and $\mathrm{Klein}^{85}$ for isolated alkyl thiolate self-assembled monolayer (H-SAM) surfaces was modified $^{76}$ to 
model hyper-thermal collisions with peptide- $\mathrm{H}^{+}$ions. The potential used for diamond is a MM force field fit to the diamond phonon spectrum. ${ }^{86}$ For perfluorinated alkyl thiolate self-assembled monolayer (F-SAM) surfaces, a MM potential was developed from ab initio electronic structure calculations for perfluoroalkanes. ${ }^{87}$

To determine accurate energy transfer probabilities from the simulations to compare with experiments, high quality intermolecular potentials between biological ions and surfaces are needed. ${ }^{88} \mathrm{MM}$ potentials such as AMBER, ${ }^{81} \mathrm{CHARMM}^{89}$ and $\mathrm{OPLS}^{90}$ "roughly" approximate the long-range, attractive two-body potentials between the atoms of the ions and surfaces, but are grossly in error for the short-range repulsions. ${ }^{91,92}$ These latter terms are important for the transfer of the ion's collision energy to the ion and surface internal degrees of freedom. ${ }^{88,93,94}$

Biological ion + surface collisions are at high energy and collisional energy transfer to the ion and surface internal degrees of freedom is determined by the ion + surface repulsive potential. For collisions of peptide- $\mathrm{H}^{+}$ions interacting with the H-SAM and diamond $\{111\}$ hydrocarbon surfaces, these potentials were derived from $a b$ initio calculations. ${ }^{95}$ The peptide- $\mathrm{H}^{+} /$surface intermolecular potential is modeled by a sum of two-body potentials between the atoms of the ion and surface. The two-body potential is given by the Buckingham repulsion and an additional repulsive term; i.e.

$$
V_{X Y}=A_{X Y} \exp \left(-B_{X Y} r_{i j}\right)+C_{X Y} / r_{i j}{ }^{n}
$$

where $X$ corresponds to $\mathrm{C}$ or $\mathrm{H}$ atoms of the diamond or H-SAM surface, $Y$ corresponds to $\mathrm{H}, \mathrm{C}$, $\mathrm{O}$, or $\mathrm{N}$ atoms of peptide- $\mathrm{H}^{+}$, and $r_{i j}$ is the distance between the atoms. To determine parameters for the above two-body potentials, ab initio potential energy curves were calculated between $\mathrm{CH}_{4}$, as a model for the $\mathrm{C}$ and $\mathrm{H}$ atoms of the diamond $\{111\}$ and $\mathrm{H}-\mathrm{SAM}$ surfaces, and $\mathrm{CH}_{4}, \mathrm{NH}_{3}$, $\mathrm{NH}_{4}{ }^{+}, \mathrm{H}_{2} \mathrm{CO}$, and $\mathrm{H}_{2} \mathrm{O}$ as models for the different types of atoms and functional groups comprising protonated polyglycine and polyalanine peptide ions. The ab initio calculations were carried out at the MP2 level of theory with the frozen-core approximation and 6-311+G(2df,2pd) basis set. The molecules were held fixed in their optimized geometries and intermolecular potential energy curves for different orientations of the $\mathrm{CH}_{4} / \mathrm{CH}_{4}, \mathrm{CH}_{4} / \mathrm{NH}_{3}, \mathrm{CH}_{4} / \mathrm{NH}_{4}{ }^{+}, \mathrm{CH}_{4} / \mathrm{H}_{2} \mathrm{CO}$, and $\mathrm{CH}_{4} / \mathrm{H}_{2} \mathrm{O}$ systems were calculated. The curves for the different orientations of a particular system were then 
fit simultaneously by a sum of the two-body functions in Eq. 2, using nonlinear least squares, to obtain the potential energy parameters.

The above approach was used to obtain potential energy curves for polyglycine and polyalanine peptide ions colliding with a F-SAM surface. ${ }^{92,96} \mathrm{CF}_{4}$ was used as a model for the surface and $\mathrm{CH}_{4}, \mathrm{NH}_{3}, \mathrm{NH}_{4}{ }^{+}$, and $\mathrm{HCOOH}$ molecules were used to model the atoms and functional groups of the peptide- $\mathrm{H}^{+}$ions. In the initial fitting, ${ }^{96}$ repulsive potential energy functions were determined as in Eq. (2). Later, ${ }^{92}$ attractive terms were included by calculating potential energy curves at the MP2/aug-cc-pVTZ level of theory and fitting these curves by the atom-surface twobody potential

$$
V_{X Y}=A_{X Y} \exp \left(-B_{X Y} r_{i j}\right)+C_{X Y} / r_{i j}{ }^{n}+D_{X Y} / r_{i j}{ }^{m}
$$

where $X$ corresponds to $\mathrm{C}$ or $\mathrm{F}$ atoms of F-SAM surface, $Y$ corresponds to $\mathrm{H}, \mathrm{C}, \mathrm{O}$, or $\mathrm{N}$ atoms of the peptide, and $r_{i j}$ is the distance between the atoms. The fitting was accomplished with a combined genetic/nonlinear least squares algorithm, with $C_{X Y} \leq 0$, for an attractive term, $D_{X Y} \geq 0$, for an additional repulsive term, and $m-n \geq 3$. The formamide molecule, $\mathrm{HCONH}_{2}$, was not included in deriving this peptide- $\mathrm{H}^{+} /$surface intermolecular potential and it was tested by using it to calculate potential energy curves for $\mathrm{CF}_{4}$ interacting with the $-\mathrm{NH}_{2}$ end of formamide and comparing these curves with those calculated with MP2/aug-cc-pVTZ theory. As shown in Figure 1 , the curves are in quite good agreement for different orientations of $\mathrm{CF}_{4}$ interacting with the $\mathrm{NH}_{2}$ group, illustrating the transferability of the derived potential energy parameters.

The potential energy function between a biological ion and surface is substantially more complex if ion + surface reactions are treated in the simulations. A QM/MM model ${ }^{84}$ was used for these simulations. A QM electronic structure theory is used for the ion, as described above, as well as part of the surface, so that reactions between the two are possible. This entails selecting a region of the surface large enough to represent the ion/surface collision and sufficiently deep to include all surface atoms participating in the ion/surface reaction. The MM model is used to include interactions between the ion and other atoms of the surface, and there is a $\mathrm{QM} / \mathrm{MM}$ interface between the QM and MM surface atoms. The QM surface region may be modified to represent reactive functional groups on the top of the surface.

\section{A.2. Method for the chemical dynamics simulations}


There are two principal components for performing the chemical dynamics simulations; one is choosing proper initial conditions for the trajectories to represent experiment and the second is the ensuing numerical integration of the classical equations of motion for the trajectories. A sufficiently large ensemble of trajectories, with random initial conditions, are calculated to obtain statistically meaningful results to compare with experiment.

The procedure for choosing initial conditions for the trajectories has been described in detail. ${ }^{95}$ A classical molecular dynamics (MD) simulation is performed for the surface so that its vibrational energy is in accord with the surface temperature $T_{s}$, usually $300 \mathrm{~K}$. The initial internal energy for the biological ion may be for a specific vibration/rotation state or sampled from a Boltzmann distribution of these states at temperature $T_{\text {ion }}$, usually $300 \mathrm{~K}$, both selected by quasiclassical sampling. ${ }^{97}$ The ion is randomly rotated about its Euler angles, and the incident collision energy $E_{i}$ and angle $\theta_{i}$ are set. The center-of-mass of the ion is then randomly aimed within the central unit-cell of the surface and numerical integration of the trajectory commences.

\section{B. Peptide- $\mathrm{H}^{+}+$surface energy transfer efficiencies}

Upon collision with the surface, there is transfer of some of the translational energy $E_{i}$ of the ion to the surface vibrations $E_{\text {surf }}$ and the ion's internal degrees of freedom $E_{\text {int }}$;

$$
E_{i}=E_{f}+\Delta E_{\text {surf }}+\Delta E_{\text {int }}
$$

where $E_{f}$ is the ion's final translational energy after collision with the surface. Numerous experiments have been performed to study energy transfer to internal degrees of freedom of biological ions in their collisions with surfaces. ${ }^{98-102}$ The simulations also provide the transfer to $E_{\text {surf }}$ and the amount remaining in $E_{f}$. Percentages of $E_{i}$ transferred to $\Delta E_{\text {int }}, \Delta E_{\text {surf }}, E_{f}$ are summarized in Table 1 for simulations that have been performed for peptide- $\mathrm{H}^{+}+$surface collisions. ${ }^{103-112}$ Uncertainties of the percentages range from 1-2\%. In the following, these energy transfer efficiencies are considered as a function of $E_{i}$ and $\theta_{i}$, the surface, peptide- $\mathrm{H}^{+}$and its size, the $V_{\text {ion }}$ intramolecular potential, and dynamics of the ion-surface collision.

\section{B.1. Collision energy}

Laskin and Futrell ${ }^{100,101}$ experimentally studied energy transfer in $\mathrm{ala}_{2}-\mathrm{H}^{+}+\mathrm{F}-\mathrm{SAM}$ collisions for $E_{i}=4.5-22.5 \mathrm{eV}$ and in des- $\mathrm{Arg}^{1}$-bradykinin collisions with H-SAM, F-SAM, and diamond $\{111\}$ surfaces for $E_{i}=15-100 \mathrm{eV}$. They found that the percentage energy transfer to 
$\Delta E_{\text {int }}$ was independent of $E_{i}$. The percentages are $21 \%$ for ala $-\mathrm{H}^{+}+\mathrm{F}-\mathrm{SAM}$ and $10.1,20.5$, and 19.2\% for des-Arg ${ }^{1}$-bradykinin colliding with the H-SAM, F-SAM, and diamond surfaces, respectively. The incident angle was normal to the surface for these experiments; i.e. $\theta_{i}=0^{\circ}$. As shown in Table 1, the simulations also give a percentage energy transfer to $\Delta E_{\text {int }}$ independent of $E_{i}$. For the $\theta_{i}=0^{\circ}$ simulations, the average percentage energy transfer to $\Delta E_{\text {int }}$ is $12 \%$ for gly $\mathrm{y}_{8} \mathrm{H}^{+}$ $+\mathrm{H}-\mathrm{SAM}, 19 \%$ for $\mathrm{ala}_{2}-\mathrm{H}^{+}+\mathrm{F}-\mathrm{SAM}$, and $21 \%$ for $\mathrm{gly}_{2}-\mathrm{H}^{+}+$diamond. These percentages agree with those measured by Laskin and Futrell. ${ }^{100-102}$

For the $\theta_{i}=45^{\circ}$ simulations, the average percentage transfer to $\Delta E_{\text {int }}$ is $12 \%$ for $\mathrm{gly}_{8}-\mathrm{H}^{+}+$ H-SAM, 23\% for ala $-\mathrm{H}^{+}+$F-SAM, 15\% for gly $2-\mathrm{H}^{+}+$diamond, $18 \%$ for $\mathrm{ala}_{2}-\mathrm{H}^{+}+$diamond, and $16 \%$ for gly $_{3}-\mathrm{H}^{+}+$diamond (the $E_{i}=10 \mathrm{eV}$ datum is not included for this last percentage).

For each of the systems studied in Table 1, the percentage remaining in translational energy decreases and the percentage transferred to the surface increases with increasing collision energy $E_{i}$. This is consistent with the time-scales for peptide- $\mathrm{H}^{+}$translation and surface vibration becoming more commensurate with increases in $E_{i}$. From another perspective, the surface appears "softer" with increasing $E_{i}$ and the collision becomes more inelastic. ${ }^{105}$

\section{B.2. $V_{\text {ion }}$ intramolecular potential}

Energy transfer simulations were performed with three different models for the peptide- $\mathrm{H}^{+}$ intramolecular potential $V_{\text {ion }}$; i.e. AMBER MM force field, and AM1 semi-empirical and MP2 $a b$

initio electronic structure theories. ${ }^{103,104,106,107}$ As shown in Table 2, within statistical uncertainties, the same average energy transfer probabilities are found with AMBER, AM1, and MP2 for gly$\mathrm{H}^{+}+$diamond collisions and AMBER and AM1 for $\mathrm{gly}_{2}-\mathrm{H}^{+}+$diamond collisions. The energy transfer distributions are also in agreement for the different $V_{\text {ion }}$, as illustrated in Figure 2 for gly gl $^{-}$ $\mathrm{H}^{+}+$diamond collisions using AMBER and AM1. This agreement suggests the collisional energy transfer is only influenced by the peptide ion's structure and forces about the ion's potential energy minimum. Details of the peptide ion's intramolecular potential are apparently unimportant for energy transfer.

\section{B.3. Incident angle}

As shown in Table 1 for the gly $\mathrm{H}_{8} \mathrm{H}^{+}+\mathrm{H}-\mathrm{SAM}$ and $\mathrm{ala}_{2}-\mathrm{H}^{+}+\mathrm{F}-\mathrm{SAM}$ collisions, energy transfer to peptide- $\mathrm{H}^{+}$is the same for $\theta_{i}$ of $0^{\circ}$ and $45^{\circ}$, showing that for the SAM surfaces energy transfer to $\Delta E_{\text {int }}$ is not dependent on $\theta_{i}$. The insensitivity in the percentage transfer to $\Delta E_{\text {int }}$ with $\theta_{i}$ may result from the high corrugation and substantial roughness of the SAM surfaces. In contrast 
to this insensitivity for transfer to $\Delta E_{\text {int }}$, the transfers to $\Delta E_{\text {surf }}$ and $E_{f}$ are affected by $\theta_{i}$, with transfer to the former decreasing and the latter increasing as $\theta_{i}$ is increased from $0^{\circ}$ to $45^{\circ}$.

In contrast to the result for the SAM surfaces, for the diamond $\{111\}$, surface energy transfer to $\Delta E_{\text {int }}$ depends on $\theta_{i}$ as shown in Table 1. For diamond, there is a decrease in the transfer to $\Delta E_{\text {int }}$ upon changing $\theta_{i}$ from 0 to $45^{\circ}$; that is, a factor of 0.66 decrease for gly- $\mathrm{H}^{+}$collisions at $70 \mathrm{eV}$ with MP2, ${ }^{107} 0.63$ decrease for $\mathrm{gly}_{2}-\mathrm{H}^{+}$at $70 \mathrm{eV}$ with AM1 and AMBER, ${ }^{104,105}$ and 0.58 decrease for gly ${ }_{8}-\mathrm{H}^{+}$collisions at $100 \mathrm{eV}$ with $\mathrm{AM} 1 .{ }^{109}$ This decrease in energy transfer is approximately the same as that expected for $\cos ^{2} \theta_{i}$ scaling, which equals 0.5 . However, for energy transfer to the surface and remaining in translation, the dependence on $\theta_{i}$ is the same as that above for the SAM surfaces.

The simulations for collisions of gly $\mathrm{H}_{8} \mathrm{H}^{+}$with the diamond surface at $E_{i}=100 \mathrm{eV}$ and $\theta_{i}$ of $0^{\circ}$ and $45^{\circ}$, in Table 1 , may be compared with experiments for des-Arg ${ }^{1}$-bradykinin colliding with the diamond surface. ${ }^{101}$ For gly ${ }_{8}-\mathrm{H}^{+}$the average percentage transfer to $\Delta E_{\text {int }}$ is $45 \%$ for $\theta_{i}=0^{\circ}$ and $26 \%$ for $\theta_{i}=45^{\circ}$. In contrast, in experiments for des-Arg ${ }^{1}$-bradykinin + diamond, with $\theta_{i}=0^{\circ}$, the transfer to $\Delta E_{\text {int }}$ is $19.2 \% .{ }^{101}$ Such different values for energy transfer to $\Delta E_{\text {int }}$ for gly ${ }_{8}-\mathrm{H}^{+}$and des$\operatorname{Arg}^{1}$-bradykinin, both octapeptides, is unexpected. This difference may arise from the perfectly flat diamond $\{111\}$ surface used for the simulations as compared with the experiment's "rough" diamond surface. ${ }^{101,112}$ The experimental surface is grown by "merging" different nucleation sites and is inherently rough. In addition, some of the carbon on the surface is graphitic and its fraction uncertain. ${ }^{113}$ Furthermore, the experimental diamond surface may have a termination that is different than the H-atom terminated surface used for the simulation. Thus, there are significant differences between the simulation and experimental surfaces. For normal collisions investigated experimentally, a perfectly flat diamond $\{111\}$ surface may transfer substantially more energy to peptide- $\mathrm{H}^{+} \Delta E_{\text {int }}$ than does a rough and irregular partially graphitic surface. However, a counter finding, from experiments, ${ }^{112}$ is that three diamond surfaces of different roughness give the same energy transfer efficiency. As discussed above, energy transfer to $\Delta E_{\text {int }}$ is not strongly affected by $\theta_{i}$ for collisions of peptide- $\mathrm{H}^{+}$ions with SAM surfaces as a result of their corrugation and roughness.

The simulations for gly $8 \mathrm{H}^{+}+$diamond with $\theta_{i}=45^{\circ}$ may be representative of collisions with a rough "diamond-like" surface. For this incident angle, the percentage energy-transfer to $\Delta E_{\text {int }}$ is $26 \%$ compared to the experimental value of $19.2 \%$. In addition, the experimental and simulation 
distributions of $\Delta E_{\text {int }}$ energy transfer are qualitatively consistent. Though the percentage of energytransfer to $\Delta E_{\text {int }}$, for des-Arg ${ }^{1}$-bradykinin is unaffected by varying the roughness of the "diamondlike" surface, ${ }^{112}$ the smoothest experimental surface still has a $32 \AA$ roughness.

\section{B.4. Peptide- $\mathrm{H}^{+}$size}

As shown in Table 1, for peptide- $\mathrm{H}^{+}+\mathrm{H}-\mathrm{SAM}$ collisions, the average percentage transfer to $\Delta E_{\text {int }}$ is weakly dependent on the peptide- $\mathrm{H}^{+}$size. For $\theta_{i}=45^{\circ}$ collisions, the percentage transfer to $\Delta E_{\text {int }}$ is 7 to $8 \%$ for gly $_{3}-\mathrm{H}^{+}$and $12 \%$ for $\mathrm{gly}_{8}-\mathrm{H}^{+}$. This result is consistent with experiments with the F-SAM, where the percentage energy transfer to $\Delta E_{\text {int }}$ for $\mathrm{ala}_{2}-\mathrm{H}^{+}$and protonated bradykinin collisions are the same within statistical uncertainties. ${ }^{100-102}$

For the simulations of $\mathrm{gly}_{\mathrm{n}}-\mathrm{H}^{+}$collisions with diamond, the energy transfer efficiency is also not strongly dependent on peptide size. As given above, the average energy transfer percentage to $\Delta E_{\text {int }}$ is $15 \%$ for gly $_{2}-\mathrm{H}^{+}, 18 \%$ for ala $2-\mathrm{H}^{+}$, and $16 \%$ for gly $\mathrm{gl}_{3}-\mathrm{H}^{+}$. From Table 1 , diamond and $\theta_{i}=45^{\circ}$ simulations were performed at single $E_{i}$ values for gly $-\mathrm{H}^{+}$, gly $5^{-} \mathrm{H}^{+}$, and gly $8^{-}$ $\mathrm{H}^{+}$, and their energy transfer percentages are 11,23 , and $26 \%$, respectively. The percentage increases from $15 \%$ for $\mathrm{gly}_{2}-\mathrm{H}^{+}$to $26 \%$ for $\mathrm{gly}_{8}-\mathrm{H}^{+}$. A statistical model which assumes the energy transfer percentage is proportional to the number of vibrational modes of the peptide ion would predict a much larger increase. As discussed below, analyses of the energy transfer dynamics suggest torsional modes of peptide- $\mathrm{H}^{+}$are efficiently excited by peptide- $\mathrm{H}^{+}+$surface collisions.

\section{B.5. Surface properties}

As summarized in Table 1, the nature of the surface is very important for the energy transfer efficiencies. A comparison may be made between collisions of gly $\mathrm{y}_{8} \mathrm{H}^{+}$with $\mathrm{H}-\mathrm{SAM}$ and diamond surfaces at $100 \mathrm{eV}$. For the H-SAM, the percentage transfers to $\Delta E_{\text {int }}, \Delta E_{\text {surf }}$, and $E_{f}$ are nearly independent of $\theta_{i}$, with values of 13,77 , and $10 \%$ for $\theta_{i}=0^{\circ}$, respectively. In contrast, for diamond these percentages are strongly dependent on $\theta_{i}$. For $\theta_{i}=0^{\circ}$ they are 45,26 , and $29 \%$, with $\Delta E_{\text {int }}$ and $\Delta E_{\text {surf }}$ receiving much more and much less energy, respectively. Similarly, a comparison may be made between ala $_{2}-\mathrm{H}^{+}$collisions with the F-SAM and diamond surfaces. For the F-SAM surface, energy transfer to $\Delta E_{\text {int }}$ is not strongly dependent on $E_{i}$ and $\theta_{i}$. For $E_{i}=22.5 \mathrm{eV}$ and $\theta_{i}=45^{\circ}$, the percentage transfers to $\Delta E_{\text {int }}, \Delta E_{\text {surf }}$, and $E_{f}$ are 23,61 , and $16 \%$. In contrast, for the diamond surface with $E_{i}=30 \mathrm{eV}$ and $\theta_{i}=45^{\circ}$, these percentages are 18,12 , and $70 \%$, with energy transfer to $\Delta E_{\text {int }}$ similar for the two surfaces, while the F-SAM receives much more energy than diamond. To summarize these comparisons, energy transfer to $\Delta E_{\text {int }}$ is similar for collisions with the F-SAM 
and diamond surfaces, with less energy transfer to $\Delta E_{\text {int }}$ for collision with the H-SAM; findings consistent with experiment. The simulations show that the H-SAM and F-SAM surfaces receive more energy than does diamond, though this has not been determined experimentally.

\section{B.6. Energy-transfer pathways and collision lifetime}

Peptide ions have a hierarchy of vibrational modes ranging from high-frequency stretches to low-frequency torsions. To assist in understanding the peptide- $\mathrm{H}^{+}+$surface energy transfer dynamics, it is useful to know which peptide modes are most efficiently excited by collisional activation. In a gas-phase simulation of exciting unfolded gly $\mathrm{y}_{4}-\mathrm{H}^{+}$by collisions with $\mathrm{Ar}$ atoms at $E_{i}=4.3 \mathrm{eV}$, the role of different types of modes on the energy transfer was investigated by increasing individual mode frequencies to the high-frequency limit, so that the modes are constrained and do not accept energy. ${ }^{114}$ With none of the vibrations constrained, $58 \%$ of $E_{i}$ is adsorbed by the peptide's internal degrees of freedom. When all of the modes are constrained, except the torsions, this is lowered to $49 \%$, which indicates the torsions absorb $\sim 84 \%$ of the internal energy transferred to the peptide.

As shown in Table 1, with none of the folded gly $_{3}-\mathrm{H}^{+}$modes constrained, 18, 9, and $73 \%$ of $E_{i}=30 \mathrm{eV}$ is transferred to $E_{i n t}, E_{\text {sur }}$, and $E_{f}$, respectively, for collision with the diamond surface. With all of the modes of $\mathrm{gly}_{3}-\mathrm{H}^{+}$, except the torsions, constrained as described above, these respective values become 14,16 , and $70 \% .{ }^{86}$ Thus, as found in the simulation of gas-phase Ar+ gly $_{4}$ energy transfer, $\sim 80 \%$ of the internal energy transferred to the peptide goes to torsions for gly $_{3}-\mathrm{H}^{+}+$diamond collisions.

In MM simulations of folded gly $y_{3}-\mathrm{H}^{+}$colliding with the diamond $\{111\}$ surface, ${ }^{95}$ average lifetimes for the collisions were determined by calculating the average change in the $\mathrm{gly}_{3}-\mathrm{H}^{+}$ internal energy versus time for the simulations' ensembles of trajectories. Results of these analyses are shown in Figure 3 for the different $E_{i}$. The average collision lifetime decreases from $\sim 1000 \mathrm{fs}$ to $\sim 220 \mathrm{fs}$, a factor of $\sim 4.5$, as the collision energy is increased from 10 to $110 \mathrm{eV}$. A simple model would assume that the gas-surface collision lifetime to be proportional to the collision velocity, i.e. proportional to $\left(E_{i}\right)^{1 / 2}$, and yielding a factor of 3.3. The simulation's decrease in the average collision lifetime is somewhat greater than this model's prediction.

\section{B.7. Collision dynamics and energy transfer models}

Model studies have been performed to investigate properties of peptide- $\mathrm{H}^{+}+$surface energy transfer dynamics. ${ }^{106,115}$ Effects of the peptide- $\mathrm{H}^{+}$vibrational temperature $T_{v i b}$ and surface 
temperature $T_{\text {surf }}$ on the energy transfer efficiency were investigated in $\mathrm{gly}_{2}-\mathrm{H}^{+}+$diamond $\{111\}$ simulations by varying both $T_{v i b}$ and $T_{\text {surf }}$ between 300 and $2000 \mathrm{~K} .{ }^{106}$ To a good approximation, the changes in $T_{v i b}$ and $T_{\text {surf }}$ had a negligible effect on the transfer of $E_{i}$ to the surface and $\mathrm{gly}_{2}-\mathrm{H}^{+}$ internal degrees of freedom.

Effects of peptide orientation and surface impact site on the efficiencies of energy transfer were studied in gly $_{2}-\mathrm{H}^{+}+$diamond $\{111\}$ simulations. ${ }^{106}$ The diamond surface has both $\mathrm{H}$ - and Csites, and energy transfer to $\Delta E_{\text {int }}, \Delta E_{\text {surf }}$, and $E_{f}$ was statistically the same for impact with the two sites. In contrast, for $\theta_{i}=0^{\circ}$ collisions, the orientation of $\mathrm{gly}_{2}-\mathrm{H}^{+}$has a significant effect on energy transfer. Initially, the peptide ion is not rotationally excited and the ion's orientation for the collision was determined by defining a vector from the $\mathrm{N}$-atom of the protonated amino group to the hydroxyl O-atom of the carboxylic group. The angle between this vector and the vector normal to the surface determined the initial orientation angle $\Psi_{i}$ of the peptide ion. When $\mathrm{gly}_{2}-\mathrm{H}^{+}$collides with its backbone vertical to the surface plane with $\Psi_{i}=90^{\circ}$ and, thus, a C-or N-terminus approach, the internal energy change is a maximum. When the ion collides horizontally, the opposite occurs. In addition, for vertical collisions more energy is transferred to the peptide ion if the C-terminus first strikes the surface instead of the N-terminus. For non-perpendicular collisions, with $\theta_{i}=45^{\circ}$, energy transfer efficiency is less sensitive to the peptide orientation. The ion orientation becomes more important as $E_{i}$ is increased. Energy transfer to $\Delta E_{\text {int }}$ versus the orientation angle $\Psi_{i}$ is well fit by the quadratic expression $\Delta E_{i n t}=a\left(\Psi_{i}-\Psi_{o}\right)^{2}+b$, where $\Psi_{o}=\sim 90^{\circ}$. For highly folded, globular peptides, there may not be a strong orientation effect for energy transfer.

As shown by the energy transfer percentages in Table 1, a good model for peptide- $\mathrm{H}^{+}+$ surface collisions versus $E_{i}$ is that energy transfer to $\Delta E_{\text {int }}$ is independent of $E_{i}$, while transfers to $\Delta E_{\text {surf }}$ and $E_{f}$ are $E_{i}$ dependent. In analyses for gly $2-\mathrm{H}^{+}$and $\mathrm{ala}_{2}-\mathrm{H}^{+}+\mathrm{F}-\mathrm{SAM}^{99}$ and $\mathrm{gly}_{8}-\mathrm{H}^{+}+\mathrm{H}-$ $\mathrm{SAM}^{101}$ collisions, the percentage energy transfer to the surface was fit by a model based on the adiabaticity parameter for $T \rightarrow V$ energy transfer. ${ }^{116}$ It was found that a more physically realistic fit was obtained if the adiabaticity parameter was related to the collision energy rather than the velocity. The model for the percentage energy transfer to the surface is then given by

$$
P_{\text {surf }}\left(E_{i}\right)=<\Delta E_{\text {surf }}>/ E_{i}=P_{o} \exp \left(-b / E_{i}\right)
$$


where $P_{o}$ (unit less) and $b$ (in $\mathrm{eV}$ ) are fitting parameters. In more complete analyses ${ }^{110}$ of the previous simulations ${ }^{108}$ of gly $\mathrm{y}_{2} \mathrm{H}^{+}$collisions with the F-SAM, $P_{o}$ and $b$ equal 0.85 and $11.83 \mathrm{eV}$ at $0^{\circ}$ and 0.72 and $6.73 \mathrm{eV}$ at $45^{\circ}$. For the gly ${ }_{8}-\mathrm{H}^{+}+\mathrm{H}-\mathrm{SAM}$ simulations, $P_{o}$ and $b$ are 0.78 and 1.87 $\mathrm{eV}$ for $0^{\circ}$ and 0.74 and $4.23 \mathrm{eV}$ for $45^{\circ}$.

\section{Fragmentation mechanisms}

QM+MM simulations identify two limiting mechanisms for SID fragmentation of peptide$\mathrm{H}^{+}$ions. ${ }^{94}$ For one, peptide- $\mathrm{H}^{+}$"shatters" as it collides with the surface, forming multiple fragments which scatter off the surface and may undergo secondary dissociations. This process is termed shattering and is practically defined within simulations as a fragmentation event that occurs faster than the vibrational period of the broken bond (this value depends on the bond). For the second mechanism, the molecule is vibrationally excited by its collision with the surface and then fragments after bouncing off the surface. If intramolecular vibrational energy redistribution $(\text { IVR })^{117}$ is complete for peptide- $\mathrm{H}^{+}$before it dissociates, its unimolecular kinetics will be in accord with Rice-Ramsperger-Kassel-Marcus (RRKM) theory. ${ }^{118}$ Between the limits of shattering and RRKM fragmentation, a range of different unimolecular dynamics is expected depending on the extent of IVR.

Shattering was observed in the gly $\mathrm{y}_{\mathrm{n}} \mathrm{H}^{+}+$diamond $\{111\} \mathrm{QM}+\mathrm{MM}$ simulations and the results are summarized in Table 3. The percentage of fragmentation which is shattering increases with increasing collision energy, illustrated by the $\mathrm{gly}_{2}-\mathrm{H}^{+}$simulations with AM1. The shattering percentage is only $8 \%$ at $30 \mathrm{eV}$, but $70 \%$ at $100 \mathrm{eV}$. Shattering occurs via multiple fragmentation channels, with as many as 304 unique products for the $\mathrm{gly}_{8}-\mathrm{H}^{+}$simulations at $E_{i}=100 \mathrm{eV}$ and $\theta_{i}=$ $0^{\circ}$. As shown in Table 3, the shattering dynamics for gly- $\mathrm{H}^{+}$at $E_{i}=100 \mathrm{eV}$ and $\theta_{i}=45^{\circ}$ with the AM1 and MP2 QM models are nearly identical. This is an important finding which highlights that qualitatively similar results are obtained using the much less computationally expensive semi empirical methods.

Shattering was observed in Fourier transform ion cyclotron resonance mass spectrometry (FT-ICR MS) experiments of des-Arg1- and des-Arg ${ }^{9}$-bradykinin SID on a F-SAM surface. ${ }^{19,120}$ At low collision energies of 15-25 eV both ions fragment via a small number of pathways, but increasing the collision energy above $30 \mathrm{eV}$ resulted in many more dissociation pathways. The same type of fragmentation dynamics was found in the simulations. Experimental time-resolved fragmentation of the ions indicated both slow and fast fragmentation, with the latter being time- 
independent and the former accurately modeled by RRKM theory. ${ }^{118}$ The kinetics of shattering fragmentation were described using a "sudden death" approximation. Sudden death is a simplified kinetic model that assumes the fragmentation rate constant is a step function of the internal energy.

Fragmentation mechanisms and energetics were analyzed for the QM+MM simulations of gly $\mathrm{n}_{\mathrm{n}}-\mathrm{H}^{+}$ions colliding with diamond. ${ }^{103,104,107,109}$ For gly- $\mathrm{H}^{+}$simulations at $E_{i}=70 \mathrm{eV}$ and $\theta_{i}=45^{\circ}$, AM1 gave three important pathways forming $\mathrm{NH}_{2} \mathrm{CH}_{2}{ }^{+}+\mathrm{C}(\mathrm{OH})_{2}, \mathrm{NH}_{3}+\mathrm{CH}_{2} \mathrm{COOH}^{+}$, and $\mathrm{NHCH}_{2}+\mathrm{H}_{2}+\mathrm{COOH}^{+}{ }^{103}$ The first is a low energy pathway, expected from energetic considerations, while the latter is a high energy pathway, occurring predominantly by shattering. For the MP2 simulations at this $E_{i}$ and $\theta_{i}{ }^{107}$ there were two important pathways $\mathrm{NH}_{2} \mathrm{CH}_{2}{ }^{+}+$ $\mathrm{C}(\mathrm{OH})_{2}$ and $\mathrm{NH}_{3}+\mathrm{CH}_{2} \mathrm{COOH}^{+}$. The MP2 simulations were also performed for $\theta_{i}=0^{\circ}$ and there were the following five important pathways listed in descending importance, with the percentage shattering in parentheses; i.e. $\mathrm{NH}_{3}+\mathrm{CH}_{2} \mathrm{COOH}^{+}(84), \mathrm{NH}_{2} \mathrm{CH}_{2}{ }^{+}+\mathrm{C}(\mathrm{OH})_{2}(41), \mathrm{NH}_{3}+\mathrm{CO}+$ $\mathrm{CH}_{2} \mathrm{OH}^{+}$(88), $\mathrm{H}_{2}+\mathrm{NH}_{2} \mathrm{CHCOOH}^{+}(100)$, and $\mathrm{NH}_{2} \mathrm{CH}_{2}{ }^{+}+\mathrm{CO}+\mathrm{H}_{2} \mathrm{O}$ (53). The first two were also the important pathways at $\theta_{i}=45^{\circ}$. The $5^{\text {th }}$ is the lowest energy pathway and expected to be the dominant pathway on energetic grounds. ${ }^{103}$ Only for pathways 2 and 5 is the vast majority of the fragmentation not shattering. From energy resolved CID experiments for gly- $\mathrm{H}^{+}$at low collision energies by Klassen and Kebarle, ${ }^{121}$ it was concluded that $\mathrm{NH}_{2} \mathrm{CH}_{2}{ }^{+}+\mathrm{CO}+\mathrm{H}_{2} \mathrm{O}$ was the most likely dissociation pathway. This pathway was not observed in the AM1 simulation and, though it was observed in the MP2 simulation, it ranked $5^{\text {th }}$ amongst the most important pathways. For later energy resolved CID experiments, Armentrout et al. ${ }^{122}$ found that the lowest energy pathway was formation of $\mathrm{NH}_{2} \mathrm{CH}_{2}{ }^{+}\left(\mathrm{H}_{2} \mathrm{O}\right)+\mathrm{CO}$ followed by formation of $\mathrm{NH}_{2} \mathrm{CH}_{2}{ }^{+}+\mathrm{CO}+\mathrm{H}_{2} \mathrm{O}$. These experiments extended to collision energies of $5.0 \mathrm{eV}$.

The differences between the gly- $\mathrm{H}^{+}+$diamond SID simulations and the gly- $\mathrm{H}^{+}$CID experiments are not surprising. The CID experiments focused on low energy collisions and determining the fragmentation threshold, which is less than $2.0 \mathrm{eV}$. The low energy CID may be fit by RRKM theory. ${ }^{122}$ In contrast, the SID simulations are at $70 \mathrm{eV}$ and the fragmentation is dominated by shattering. It is possible that none of the fragmentation is statistical and in accord with RRKM theory.

For the gly- $\mathrm{H}^{+}$and $\mathrm{gly}_{2}-\mathrm{H}^{+}+$diamond simulations, ${ }^{103,104,107}$ trajectories were analyzed to identify which backbone bond rupture initiated the fragmentation. The specific a- and x-type ions formed by the gly $-\mathrm{H}^{+}$and $\mathrm{gly}_{2}-\mathrm{H}^{+}$fragmentations, and the following gly $8-\mathrm{H}^{+}$fragmentation, are 
given in the research articles and not listed here. For the AM1 gly- $\mathrm{H}^{+}$simulations, ${ }^{103}$ the predominant initial backbone rupture was the ${ }^{+} \mathrm{H}_{3} \mathrm{NCH}_{2}---\mathrm{COOH}$ bond, with a small amount of ${ }^{+} \mathrm{H}_{3} \mathrm{~N}---\mathrm{CH}_{2}$ bond rupture forming $\mathrm{NH}_{3}+\mathrm{CH}_{2} \mathrm{COOH}^{+}$. For the MP2 gly- $\mathrm{H}^{+}$simulations, ${ }^{107}$ the former initial bond rupture remains dominant, but ${ }^{+} \mathrm{H}_{3} \mathrm{~N}---\mathrm{CH}_{2}$ bond rupture is more important than for the AM1 simulations.

At $E_{i}=30 \mathrm{eV}$, for the gly $2-\mathrm{H}^{+}+$diamond simulations, ${ }^{104+} \mathrm{H}_{3} \mathrm{NCH}_{2}---\mathrm{CONHCH}_{2} \mathrm{COOH}$ bond rupture is the only important initial bond dissociation pathway. At higher $E_{i}$, this remains the most important initial backbone bond cleavage, but the initial cleavage now occurs at all of the backbone bonds except ${ }^{+} \mathrm{H}_{3} \mathrm{NCH}_{2} \mathrm{CONH}---\mathrm{CH}_{2} \mathrm{COOH}$. From the simulations, at $E_{i} \leq 70 \mathrm{eV}$, $\mathrm{NH}_{2} \mathrm{CH}_{2}{ }^{+}$and its isomer $\mathrm{NH}_{3} \mathrm{CH}^{+}$are the principal fragment ions, consistent with collision energy resolved gly $2-\mathrm{H}^{+} \mathrm{CID}$ experiments. ${ }^{121}$ However, from the experiments it was proposed that the initial backbone cleavage for formation of these ions is the peptide bond, while the dominant initial cleavage from the simulations is the ${ }^{+} \mathrm{H}_{3} \mathrm{NCH}_{2}---\mathrm{CONHCH}_{2} \mathrm{COOH}$ bond.

Initial bond rupture dissociation sites were not determined for the $\mathrm{gly}_{8}-\mathrm{H}^{+}$simulations, but backbone cleavage patterns were determined. ${ }^{109}$ Most of the fragmentations are shattering, with most occurring by two or three backbone cleavages. An important component of these simulations was analyses of product fragment rearrangements, a problem for peptide sequencing. ${ }^{123-125}$ Two rearrangement mechanisms were observed. One involves an initial association of the termini of a fragment, forming a cyclic structure. This intermediate then dissociates via a different backbone cleavage site, altering the backbone sequence. For the second, fragments recombine while they are near the surface.

Shattering was observed in QM/MM simulations of $\mathrm{gly}_{2}-\mathrm{H}^{+}$colliding and reacting with a F-SAM surface, with reactive $-\mathrm{C}(\mathrm{O}) \mathrm{Cl}$ and $-\mathrm{C}(\mathrm{H}) \mathrm{O}$ head groups. ${ }^{126}$ However, the shattering percentage was not determined, given the difficulty in deconvoluting shattering and reactive trajectory events. There was no shattering in a simulation of gly $\mathrm{y}_{8} \mathrm{H}^{+}$collisions with a "soft" $\mathrm{H}-$ SAM surface. ${ }^{110}$ However, there was non-shattering fragmentation promoted by proton transfer. ${ }^{127}$ The most important fragmentation pathways were cleavages of $\mathrm{CH}_{2}--\mathrm{CO}$ and peptide bonds.

The mobile proton model is based on the concept that collisional excitation populates a thermodynamically less favorable conformation inducing proton transfer to less basic sites. As a consequence, the covalent bond adjacent to the final site is weakened and often breaks. Studying proton motion was the focus of Barnes' and co-workers ${ }^{128}$ simulation of gly ${ }_{8}-\mathrm{H}^{+}+\mathrm{F}-\mathrm{SAM}$ SID. 
By carefully tracking motions of protons within the peptide and correlating proton motion to subsequent bond cleavage events, information was gained regarding the number of proton transfers required prior to fragmentation as well as the most probable sites for proton migration. Proton migration was considered relevant to a backbone cleavage event if the proton moved to or from either of the heavy atoms involved in the bond or a heavy atom connected to those involved. It was found that at collision energies of both 30 and $110 \mathrm{eV}$, nearly $50 \%$ of the backbone cleavage events occurred after a single proton hop. It was also observed that there was a striking even-odd nature regarding which hops were efficient. This feature was due to competition between two or more protonation sites. This may be illustrated through a simple example of two states, denoted A and $\mathrm{B}$, which could be competing for a proton (the generalization to more sites is straightforward). Simulations showed that the first proton transfer frequently resulted in fragmentation, i.e $\mathbf{A} \rightarrow \mathbf{B}$ where the bold B denotes that fragmentation occurred from that protonation state. However, if insufficient energy was present in the relevant covalent bond, protonation state A could recover the proton, and if it was the initial, stable protonation site, the peptide ion was unlikely to fragment. Hence, the sequence $\mathrm{A} \rightarrow \mathrm{B} \rightarrow \mathrm{A} \rightarrow \mathbf{B}$ leading to fragmentation becomes likely and justifies the even-odd fragmentation efficiency observed.

It is also noteworthy that qualitatively similar hop efficiencies are seen at 30 and $110 \mathrm{eV}$, suggesting the fragmentation mechanism is collision energy independent. The lag time between proton hop and fragmentation was also modeled using a simple kinetic scheme. It was found that $90 \%$ of the trajectories fragment within $1.5 \mathrm{ps}$ of a relevant proton hop at $110 \mathrm{eV}$. To reach the same fragmentation fraction, following a relevant proton hop at $30 \mathrm{eV}, 2.5 \mathrm{ps}$ is required. This illustrates that as long as sufficient energy is transferred, the mechanism is collision energy independent but the reaction rate is dependent of the available energy.

In related work, ${ }^{129}$ dynamics that take place following initial fragmentation events was examined. It was seen that fragmentation products were able to form complexes rather than simply drifting apart, a finding similar to that discussed above for gly ${ }_{8}-\mathrm{H}^{+}$fragmentation. ${ }^{109}$ These complexes typically were stabilized via hydrogen bonding between the charged and neutral fragment species. The presence of these complexes opened the possibility for secondary reactions leading to products that are only possible through complex formation. These non-covalent complexes have long lifetimes and specifying an average lifetime in units of time is misleading. Simulations necessarily examine a relatively short time window and the initial fragmentation event 
may occur either early or late within the simulation. Hence, a lifetime fraction was defined relative to the total time the complex exists within the simulation. It was found that the average lifetime fraction was $83 \%$ at $30 \mathrm{eV}$ and $55 \%$ at $110 \mathrm{eV}$. Some secondary fragmentation products resulted from combination of traditional intramolecular mobile proton motion along with intermolecular proton transfer between charged and neutral fragments. Formation of such complexes may play an important role in the overall reaction mechanisms of SID and CID.

\section{Soft landing}

In simulations of ala $-\mathrm{H}^{+}$colliding with a FSAM consisting of $\mathrm{CF}_{3}-\left(\mathrm{CF}_{2}\right)_{7}-\mathrm{S}$ - chains, SL was studied. ${ }^{11,130}$ The $V_{\text {ion-surface }}$ potential used for the simulation included both accurate longrange attractive and short-range repulsive terms. In a separate molecular dynamics (MD) simulation of ala $_{2}-\mathrm{H}^{+}$desorbing from this surface, ${ }^{131}$ the ala $_{2}-\mathrm{H}^{+} / \mathrm{F}-\mathrm{SAM}$ binding energy was found to be $\sim 13 \mathrm{kcal} / \mathrm{mol}$. When $\mathrm{ala}_{2}-\mathrm{H}^{+}$is thermally equilibrated on the surface, its shape and size changes, becoming less compact by cleavage of a hydrogen bond between the - $\mathrm{OH}$ and $-\mathrm{NH}-$ groups. Of particular interest with respect to SL, is the percentage of trajectories which remained trapped on/in the F-SAM when the $\mathrm{ala}_{2}-\mathrm{H}^{+}+$FSAM trajectories were terminated at $10 \mathrm{ps} .{ }^{111}$ The percentage of trajectories which remain trapped decreases with increasing $E_{i}$. At $70 \mathrm{eV}$ there are no trapped trajectories. For $\theta_{i}=0^{\circ}$ collisions, $84,65,41$, and $29 \%$ of the trajectories remained trapped at $E_{i}$ of $5,13.5,22.5$, and $30 \mathrm{eV}$, respectively. The percentage of the trajectories which are trapped decreases upon changing $\theta_{i}$ from $0^{\circ}$ to $45^{\circ}$. This decrease is small at $E_{i}=5 \mathrm{eV}, 84$ to $69 \%$, but large at $E_{i}=22.5 \mathrm{eV}, 41$ to $6 \%$.

Mechanisms for trapping (SL) of $\mathrm{ala}_{2}-\mathrm{H}^{+}$on the F-SAM include physisorption on top and penetration of the F-SAM. ${ }^{130}$ Five different mechanisms were identified for $E_{i}=5$ and $13.5 \mathrm{eV}$, and $\theta_{i}=0^{\circ}$, for which trapping is important: (i) first physisorption, followed by penetration, and then physisorption when the trajectory is terminated (i.e., phys-pen-phys); the remaining four mechanisms are (ii) pen-phys-pen; (iii) pen-phys; (iv) phys-pen; and (v) only phys. For the $84 \%$ of the trajectories trapped for the $5 \mathrm{eV}$ simulations, $40 \%$ first penetrate and $44 \%$ first physisorb. The pen-phys-pen, pen-phys, phys-pen, and phys mechanisms have similar probabilities. At 13.5 $\mathrm{eV}, 65 \%$ of the trajectories are trapped, with $47 \%$ first penetration and only $18 \%$ first physisorption. The pen-phys mechanism dominates and the phys-pen mechanism, important at 5 $\mathrm{eV}$, is unimportant. A significant fraction of the 11 heavy atoms of $\mathrm{ala}_{2}-\mathrm{H}^{+}$penetrate the F-SAM, when ala $-\mathrm{H}^{+}$is trapped. Most of the penetration occurred near the top of the $\mathrm{CF}_{3}-\left(\mathrm{CF}_{2}\right)_{7}-\mathrm{S}$-chains. 
For the $30 \mathrm{eV}$ simulation, penetration is only as deep as the second layer. For the $E_{i}=70 \mathrm{eV}$ simulation, there is deep penetration to the $5^{\text {th }}$ layer, but as discussed above there is no trapping.

Barnes and co-workers ${ }^{132}$ conducted simulations of Ac-ala $7-1 y s-\mathrm{H}^{+}$and Ac-lys-ala $7-\mathrm{H}^{+}$soft landing on an F-SAM surface using the same interaction potential as Hase and co-workers. ${ }^{92}$ While Ac-ala-lys and Ac-lys-ala 7 have similar composition, their secondary structures are dramatically different. In particular, Ac-ala-lys is the shortest stable alpha-helical polyalanine chain, whereas Ac-lys-ala 7 has a random coil or globular structure. The close similarity in sequence allows for an analysis of the effect of secondary structure on the SL efficiency. Trajectories were classified in a similar way as for the ala $2-\mathrm{H}^{+}$simulations, ${ }^{111,130}$ however, an additional "intermediate" class was included. Intermediate trajectories may eventually soft land or escape the surface, but their ultimate fate cannot be determined within the time frame of the simulation. The population within this class was minimal.

It was found that the soft-landing efficiency was nearly identical between Ac-ala-lys- $\mathrm{H}^{+}$ and Ac-lys-ala $7-\mathrm{H}^{+}$, meaning secondary structure had little effect. A fast conformational change upon interaction with the surface was observed for both species. This change was quantified by defining a time dependent conformational entropy via an approach inspired by the work of Baxa et al. ${ }^{133}$ The time dependent probability distribution for the Ramachandran angles of each peptide was calculated, which allowed for the entropy to be determined according to the statistical definition, namely $S(t)=-k_{B} \sum_{i} P_{i}(t) \ln \left(P_{i}(t)\right)$, where $P_{i}(t)$ is the time dependent probability of having a Ramachandran angle within in the $\mathrm{i}^{\text {th }}$ bin (see Ref. 132 for greater detail). Although both secondary structures underwent fast conformational changes, the alpha-helical peptide produced more entropy throughout the course of the simulations. At the end of the simulations, both species approached a similar "globular" structure.

No significant penetration into the surface was observed at the collision energies considered, and hence the mechanism for soft landing was through physisorption to the surface. In addition, a "tethering" mechanism was observed. In this mechanism one portion of the peptide was strongly attracted and close to the surface - the tethering point, while another portion drifted quite far away before being tugged back and ultimately remaining close to the surface. In other words, without the strong attractive interaction at the tethering point, the peptide would not SL to the surface. This type of attachment mechanism is likely more common for larger peptides, explaining why it was not seen for the $\mathrm{ala}_{2}-\mathrm{H}^{+}$work. 


\section{E. Reactive landing}

Reactive landing (RL) has been studied via simulations for several model systems. ${ }^{126,134,135}$ In order to include reactivity between the surface and the peptide, it was necessary to make some modifications to the general approach outlined above. Namely, it was a requirement to include some atoms of the surface along with all of the atoms of the peptide in the QM calculation. In these simulations, it is typical for the propyl-tip of the center chain to be included in the QM region via the linking atom approach. The first study involving this approach studied $\mathrm{gly}_{2}-\mathrm{H}^{+}$colliding with a chemically modified F-SAM using RM1 semi-empirical theory. Two different chemical modifications were considered in which an $\mathrm{F}$ atom on the terminal $\mathrm{C}$ is replaced by either a $\mathrm{C}(\mathrm{O}) \mathrm{Cl}$ or a $-(\mathrm{O}) \mathrm{H}$ moiety. These modifications were chosen to examine the effect of the "leaving group" (either $\mathrm{Cl}$ or $\mathrm{H}$ ) on reactivity. A later study also considered the H-SAM system. Reactivity was significantly higher for the $-\mathrm{C}(\mathrm{O}) \mathrm{Cl}$ modification than for $-\mathrm{C}(\mathrm{O}) \mathrm{H}$.

Simulations showed that reactivity took place through a 4-centered transition state, which is not common. The TS involves forming two new bonds while simultaneously breaking two old bonds. In particular, the bonds that break involve an $\mathrm{X}-\mathrm{H}$ bond on the peptide and a $\mathrm{C}-\mathrm{Y}$ bond on the surface where $\mathrm{Y}$ is a "leaving group." This is consistent with the observation that the $-\mathrm{C}(\mathrm{O}) \mathrm{Cl}$ moiety was more reactive, as $\mathrm{Cl}$ is a better leaving group. For both studies, good qualitative agreement was found with Laskin and coworkers experimental work. ${ }^{136}$

Recently, Barnes and co-workers studied RL for the cyclic peptide c(-GGKG-) for both neutral and +1 charged states. ${ }^{135}$ This study represents the most direct comparison to work of Laskin and co-workers. ${ }^{136}$ The work found that overall reactivity increased with collision energy, which would disagree with experiment. However, the experiment is not measuring total reactivity, but rather reactions in which the peptide reacted and remained intact. When examining this type of reaction within the simulations, good qualitative agreement was found with experiment. As in prior work, ${ }^{110}$ RL occurs through a 4-centered transition state.

Differences were seen between the neutral and charged species. In particular, the binding site on the peptide is different and RL is more likely for the neutral species than for the charged species. Given the size and cyclic nature of this system, the excess proton was placed on the lysine side chain. The basic nature of this amino acid served to deactivate RL at lysine, which accounts for the reactivity difference between the two species. This work also examined the effect of 
including more chains in the QM region. Specifically, rather than including just the center chain, some simulations included it as well as the 8 nearest neighbor chains. For the charged species, nearly all of the RL events occur on the center chain, while for the neutral species roughly half occur on the surrounding chains. It is also striking that for the charged species, the covalent linking site is almost exclusively on the peptide backbone N's and O's, while for the neutral it is most likely to occur on the lysine side chain's $\mathrm{N}$.

Lastly, we note that the simulation of the neutral species provides physical insight for the behavior of a large, charged species that happens to have a point of contact with the surface far from the charged site.

\section{Collision-Induced Dissociation}

Extensive simulations have been performed to study the CID of organic and biological ions. The simulation results have not been previously compared together and summarized. This is done here in the context of describing the role of chemical dynamics simulations for CID experiments.

\section{A. Energy transfer to vibration and rotation}

In CID, a crucial aspect is the energy that is transferred upon collision between the ion and the inert gas, which generally is a rare gas $(\mathrm{Ar}, \mathrm{Ne}, \mathrm{Xe} \ldots)$ or molecular nitrogen $\left(\mathrm{N}_{2}\right)$. During the collision, the ion is internally activated and can dissociate. Just as in SID, the probability of dissociation and the fragmentation mechanism are related to (at least) three aspects: (i) the amount of energy that is transferred after each collision; (ii) the partitioning between vibrational and rotational activation; (iii) the localization of the energy after the collision in a particular internal mode and the way this energy flows through the other modes. This last aspect will be discussed in section III.B, here we will first focus on what information simulations can provide regarding the energy transfer process.

Using chemical dynamics simulations, it is possible to directly model the collision between an ion and the inert gas. In particular, single collisions are studied and the collision energy is fixed as an input parameter. This collision energy, in the center-of-mass frame, can be related to the collision energy in the laboratory frame used in triple-quadrupole mass spectrometer: ${ }^{137}$

$$
E_{\text {com }}=\frac{m_{\text {gas }}}{m_{\text {ion }}+m_{\text {gas }}} E_{l a b}
$$


where $E_{c o m}$ and $E_{l a b}$ are the energies in the center-of-mass and in the laboratory frame, respectively, and $m_{i o n}$ and $m_{\text {gas }}$ are the masses of the ion and the inert gas, respectively. In this way, it is possible to make a direct correspondence between collisional simulations and MS/MS experiments done as a function of the collision energy. The collision energy is experimentally often reported in the laboratory frame and can be easily converted into center-of-mass frame via Eq. 6.

Part of the collision energy is transferred to the ion which is rovibrationally activated. The ion-gas interaction is generally described using an analytical function, similarly to SID (see section II.A.1). Often the analytical expression in Eq. 2 is used where $A_{X Y}, B_{X Y}$ and $C_{X Y}$ are obtained by fitting interaction energies calculated $a b$ initio and $n$ can be either fixed or a parameter of the fit. Generally, the best fits are obtained for positive values for $A_{X Y}, B_{X Y}$ and $C_{X Y}$, which leads to a purely repulsive potential. The attractive part of the interaction is often disregarded since it is much smaller than the collision energy and to model the energy transfer it is very important to correctly reproduce the repulsive short-range potential. More details on this aspect can be found in Ref. 88 .

When studying relatively large molecules, like peptides, a building block approach is used: ${ }^{88}$ the interaction of the inert gas with $\mathrm{CH}_{4}, \mathrm{NH}_{3}$ and other elements is obtained from high level calculations (e.g. QCISD(T)). Generally, the interaction is set for each hybridization or chemical environment: for $\mathrm{C}$ there are values for $\mathrm{sp}^{3}$ and $\mathrm{sp}^{2}$, for $\mathrm{H}$ the values are function of the group to which it is attached etc ... Using this approach, and fixing $n=9$, Meroueh and Hase have developed and reported the interaction potential between $\mathrm{Ar}$ and building blocks of polyglycines. ${ }^{88}$ Using the same functional form and approach, parameters for Ar interacting with aromatic rings, the sulfur atom, and some alkaline and alkaline-earth metals $\left(\mathrm{Li}^{+}, \mathrm{Ca}^{2+}\right.$, and $\left.\mathrm{Sr}^{2+}\right)$ have been obtained. ${ }^{138-141}$ The same functional form was also used to study $\mathrm{N}_{2}$ colliding with protonated urea. $^{142}$

Other analytical expressions are used in the literature as for SID. For example, de Sainte Claire et al. ${ }^{143}$ used Eq. 3 with $n=6$ and $m=12$ in studying the collision of Ar with Al clusters, and Rodriguez-Fernandez et al. ${ }^{144}$ used the same Eq. 3 where $n$ and $m$ were also fitted to study the collision of Ar with $[\mathrm{Li}(\mathrm{Uracil})]^{+}$cluster. Knyazev and $\operatorname{Stein}^{145}$ have used the analytical expression of Eq. 3 with $n=9$ and $n=6$ and parameters obtained by high level $a b$ initio calculations. In this way, they successfully studied the reactivity of n-Butylbenzene in CID. 
More recently, for CID of a doubly protonated tripeptide, $[\mathrm{TIK}+2 \mathrm{H}]^{2+}$, with $\mathrm{N}_{2}$, a full semiempirical Hamiltonian (RM1) was used. ${ }^{146}$ Semi-empirical methods can provide correct interactions for $\mathrm{N}_{2}$, but they are incapable of treating rare gas atoms. The choice of a full semiempirical Hamiltonian (like RM1) or an analytical expression depends essentially on the availability of empirical (molecular mechanics, MM) parameters. Results of RM1 and MM for the simple case of $\mathrm{N}_{2}$ colliding with $\mathrm{CH}_{3} \mathrm{OH}$ show that both methods provide short-range interaction energies within 10-30 $\mathrm{kcal} / \mathrm{mol}$ with respect to accurate QCISD(T)/6-31++G** calculations (see Figure 4).

In Table 4 we summarize results obtained in recent years for different systems using Eq. 2 or semi-empirical Hamiltonians to treat the ion-gas interaction. The average $\%$ of the transferred energy is reported. Values are often significantly smaller than $50 \%$ and they decrease as the collision energy increases. In fact, with increasing collision energy, the relative velocity also increases and thus the ion-neutral interaction time. While the average energy transfer is relatively small, the distribution is generally broad. As a result, some trajectories get a large portion of the collision energy. These trajectories are mostly reactive trajectories. An example of the distribution for the total energy transferred for reactive and non-reactive trajectories is shown in Figure 5.

Another important aspect which can be studied in such simulations is the partitioning between collisionally acquired rotational and vibrational energy. This information is important when studying the statistical reactivity of activated ions using simulation results. In fact, in RRKM unimolecular dissociation statistical theory, the rate constant is function of both vibrational and rotational internal energy. ${ }^{118}$ Rotational energy is often disregarded in practical RRKM calculations since in many cases the rotational activation is low and its effect on the rate constant is important only for higher values and/or when the rotational constants (and thus shapes) of reactant and transition state are very different. Note that when analyzing guided ion beam mass spectrometry experiments with statistical theory, the rotational energy has been taken into account, as reported by Armentrout and co-workers. ${ }^{147,148}$ These studies pointed out that a phase space theory approach, in which rotational and orbital angular momentum are explicitly conserved and allowed to interchange, is successful in reproducing the data, even if they also show that the assumptions on angular momentum have no effect on thermodynamic information. ${ }^{149-155}$

In general, it is not evident how the partitioning between rotational and vibrational energy results after collisional activation. Simulations can provide information on those aspects. In studies 
on Al clusters and small peptides, it was shown that the rotational excitation is higher in case of planar shapes while it is smaller for globular ones. ${ }^{114,143}$ Later, simulations of collisions between protonated urea, uracil and Li-uracil have shown that rotational energy excitation is important. ${ }^{142,144,156}$ A summary of the percentage of rotational energy transfer for different systems we have studied in recent years is reported in Table 4. We should note in particular that rotational excitation is more important for small molecules and it decreases as the collision energy increases. This dependence is shown in more details in the study of collisions of protonated uracil with Ar. ${ }^{156}$ For low collision energies, the rotational excitation is more important while, with increasing the energy, the vibrational excitation becomes dominant (see Figure 2 of Ref. 156). Using data from simulations at different collision energies, it is possible to fit the following analytical phenomenological expression to extrapolate the energy transfer at different values of $E_{c o m}$ :

$\langle\Delta E\rangle=a_{1} e^{-b_{1} / \sqrt{E_{c o m}}}+a_{2}\left[\operatorname{csch}\left(\frac{b_{2}}{\sqrt{E_{c o m}}}\right)\right]^{2}$

where $a_{1}, a_{2}, b_{1}$ and $b_{2}$ are adjustable. This expression was originally developed to study the energy transfer to solid surfaces ${ }^{157}$ but it can be applied also to CID, since it is an extension of the original Mahan impulsive collision model. ${ }^{93}$ Nogueira et al. have thoroughly tested this expression in largescale simulations of SID with different projectiles. ${ }^{158}$

Once the energy is transferred to the molecule after collision, this energy is available to promote fragmentation. As for SID, two main classes of fragmentation mechanisms can be defined: (i) shattering mechanisms; (ii) energy flow through the modes corresponding (in the limit of full IVR) to a statistical energy distribution and associated unimolecular decomposition. In this case one expects a RRKM behavior.

We now show how collisional dynamics can unravel the presence of shattering mechanisms and how they are important in understanding CID fragmentation.

\section{B. Shattering fragmentation}

As previously discussed, it is possible that a shattering fragmentation occurs (see section II.C). For peptides, trajectories reacting in less than $40 \mathrm{fs}$ can be defined as shattering. ${ }^{159}$ In fact, if the bond has no time to vibrate there is also no time for the energy to flow from this mode to other vibrational modes. This mechanism was initially observed in SID simulations but also in the 
collision between a molecular ion and the inert neutral gases. This is a typical example of nonRRKM dynamics due to collisional activation, which is localized in space: the portion of the molecule where the projectile hits the ion can quickly react. Concerning small molecules, shattering dissociations and non-RRKM dynamics have been observed in experiments ${ }^{160}$ and simulations ${ }^{161}$ of $\mathrm{CH}_{3} \mathrm{SH}^{+}+\mathrm{Ar} \mathrm{CID}$, experiments ${ }^{162}$ and simulations ${ }^{163}$ of $\mathrm{CH}_{3} \mathrm{SCH}_{3}{ }^{+}+\mathrm{Ar} \mathrm{CID}$, and simulations ${ }^{164-166}$ of $\mathrm{Cr}^{+}(\mathrm{CO})_{6}+\mathrm{Xe}, \mathrm{H}_{2} \mathrm{CO}^{+}+\mathrm{Ne}$ and $\mathrm{UreaH}^{+}+\mathrm{Ar} \mathrm{CID}$. Moving to larger molecules, the first direct dynamics study of CID was performed by Meroueh et al. ${ }^{103}$ where they compared CID with SID fragmentation of protonated glycine. CID simulation with Ar at $13 \mathrm{eV}$ of collision energy and for zero impact parameter did not report shattering, while SID did.

In our recent studies, some shattering fragmentations were observed as reported in Table 4 as a function of the system and the collision energy. The fraction of shattering fragmentation increases with the collision energy (as expected) and that it is quite high for large molecules, like penta- and octa-glycines. ${ }^{167}$ This high percentage is due partially to the reaction of the molecular tails, which are more exposed to the collision and thus they react due to a localized collision. Further, for such big systems, complete IVR is relatively slow and in the given simulation time it is less probable to observe trajectories in which the energy has time to redistribute and induce a fragmentation. In some cases, the first fragmentation occurs with a shattering mechanism, as for the $\mathrm{NH}_{3}$ loss in amine-substituted diglycine, which forms the linear $\mathrm{b}_{2}{ }^{+}$ion that then cyclizes into the well-known oxazolone structure, as observed for diglycine (see Figure 6). ${ }^{168}$ A full pathway leading to an observed fragment can be composed of two steps: a first (shattering) in which a part of the molecule dissociates and a second (rearrangement as in the example of Figure 6) which forms the final structure. Of course, mechanisms can be more complex, since mixing of shattering and non-shattering can be involved, and, for example, isomerization can occur before fragmentation (as often is the case for peptides).

Shattering can be an important dynamical mechanism which cannot be accounted for using statistical theories. Thus, studies of the potential energy surface of different dissociation pathways can underestimate the probability of a pathway where shattering occurs. ${ }^{140}$ On the other hand, limitation in simulation time-length is a source of overestimation of shattering fragmentations. To better include events at longer time, a statistical treatment is also necessary, as will be discussed in following sections.

\section{Comparison with experiments}


Chemical dynamics simulations provide the relative abundance of fragmentation products as a function of collision energy. This data provides a means to directly compare with experimental results.

Our first example is the fragmentation of protonated urea, for which collisional dynamics simulations, done at MP2 level of theory, were compared with experiments. ${ }^{166}$ Experiments were performed on a QqTOF instrument which operates at low pressure close to the single collision limit. In this case, the fragmentation pattern was simple, consisting of two pathways: (1) neutral ammonia loss and formation of the $\mathrm{CONH}_{2}{ }^{+}$ion $(\mathrm{m} / \mathrm{z} 44)$; (2) formation of $\mathrm{NH}_{4}{ }^{+}$ions $(\mathrm{m} / \mathrm{z} 18)$ and neutral CONH. Pathway (2) is energetically favorable, but in experiments and simulations we obtained both pathways. From simulations it was possible, in particular, to explain why the highenergy pathway was observed: it is obtained by the cleavage of $\mathrm{C}-\mathrm{N}$ bond followed by $\mathrm{NH}_{3}$ loss, and this happens via a shattering mechanism. By hitting the molecule on that bond, if the leaving $\mathrm{NH}_{3}$ group escapes with a sufficiently high translational energy it has no time to pick a proton from the $\mathrm{NH}_{2}$ group forming $\mathrm{NH}_{4}{ }^{+}$and neutral $\mathrm{NHCO}$. This mechanism, elucidated for the first time in the prototypical case of protonated urea, was then obtained for other systems, in particular in protonated peptides in which the protonated $\mathrm{N}$-terminal group can lead to $\mathrm{NH}_{3}$ loss before any other internal rearrangement. ${ }^{168}$

The same approach was used to examine fragmentation of protonated peptides. In the case of amino-substituted protonated di- and tri-glycines, we coupled our simulations with CID experiments and ion spectroscopy (IRMPD) used to characterize the structure of the precursor ion and of some products. ${ }^{168}$ Simulations and experiments obtained the same product structures, and the mechanisms suggested from experiments were observed in chemical dynamics simulations. In the case of peptide fragmentation, the experimental literature agrees with the "mobile proton model", ${ }^{127}$ described in section II.C. From simulations, it was possible to observe the characteristic features of the mobile proton model in two steps: (i) we observed some proton transfers by populating high-energy tautomers; (ii) we used these tautomers as initial structures in further simulations, obtaining new fragmentation products. One key aspect is that the initial protonation site is more important in determining the final products than the conformation of each tautomer. This was observed not only in peptides but also in uracil. ${ }^{141}$ A proton transfer (PT) is a process that is generally slow with respect to the simulation time scale. If one PT is obtained, then a second reaction (or even a second PT) has a very low probability to be observed in simulations, mainly 
due to the limitation in simulation time. Thus, putting together simulations done using different tautomers as initial structures, it is possible to reconstruct the full fragmentation scheme and understand the origin of the observed products. ${ }^{169}$ Of course, by increasing the simulation time, it is also possible to obtain several proton transfers and related fragmentation.

One characteristic gas phase reactivity of peptides is that, when the linear $b$ ion is formed by $\mathrm{C}-\mathrm{N}$ bond cleavage, then there are two possible nucleophilic attacks leading to two different cyclic structures: (i) the 5-member ring oxazolone and (ii) the 6-member ring diketopiperazine, which is energetically more stable (but not observed in many cases). ${ }^{45,49,170-172}$ Simulations of polyglycines and N-Formylalanylamide provide as product the oxazolone in agreement with experiments. ${ }^{167-169}$ More recently the negative ion of deprotonated di-proline was studied, and the diketopiperazine $b_{2}$ ion was obtained from simulations, in agreement with IRMPD experiments probing the molecular structure of such a product. ${ }^{173}$

Another successful performance of collision dynamics in reproducing CID spectrum and products of biologically relevant molecule is the study of protonated testosterone. ${ }^{174}$ First, the fragment peak distribution obtained from simulations is very similar to what is obtained experimentally (see Figure 7). ${ }^{175}$ Second, from simulations it was possible to determine the mechanisms leading to the different pathways, which provided computational conformation of some of them. ${ }^{175-177}$ Finally, the simulations find the same geometries obtained experimentally by IRMPD spectroscopy, thus strengthening our confidence in the other structures (and associated mechanisms) for which no experimental details are available. This study gives us confidence in using collisional simulations to study other similar systems in the future, with possible applications to metabolomics or characterization of doping substances.

As clearly shown from the study of testosterone, but also true in other systems, the simulations reproduce fairly well the experimentally obtained fragments, but often the intensity of the peaks is very different. The reasons are briefly summarized here:

1) The ab initio computational method employed is, by necessity, approximate in nature, since fully correlated methods (and the completed basis set limit) are computationally intractable for use in these direct dynamics simulations. In practice, it is possible to use DFT or MP2 with relatively small basis set for small molecules and semi-empirical Hamiltonians for larger systems. Comparisons between DFT and semi-empirical Hamiltonians were done in some cases, as we will discuss in section III.E. 
2) The limitation in simulation time-scales is another source of discrepancy. Direct dynamics trajectories are limited to picoseconds, while, in experiments, fragmentations occur up to milliseconds. As already mentioned, the shattering fragmentations can be overestimated and thus the peaks which are not formed via shattering can have a much lower occurrence in simulations. To include longer time-scale fragmentation events, RRKM theory was also included in some studies when the transition states (TSs) connecting the reactant with the products were located. ${ }^{140,156}$ Recently, Martinez-Nunez has developed an automatic algorithm to find minima and TS from simulations using high-temperature trajectories to sample the configuration space, ${ }^{178-180}$ which was applied to the case of CID of protonated uracil. ${ }^{156}$ Coupling it directly with the collisional dynamics is a clear possibility and a recent first study was reported for cysteine-sulfate fragmentation. ${ }^{181}$ However, this method cannot be used if a pathway is not observed in simulations and the usual approaches to determine reaction pathways and TSs must be used, which can be very problematic for large and flexible systems.

3) Collisional simulations are done in the single collision limit, while in experiments multiple collisions occur often. Many experiments are done in ion traps in which the activation mode is different and the collision energy is not clearly defined. This will be discussed in next section.

4) Finally, experimentally, the intensity of fragments depends on many details, including the mode of ionization and source conditions, ion transmission and detection, mode of collisional excitation, and time between ion activation and analysis. This phenomenon can be seen in the simple example of fragmentation of the simple protonated uracil molecule, ${ }^{141,182-184}$ where the reaction mechanisms were elucidated by simulations. The aim of modeling CID is to provide a global framework to understand the fragmentation mechanisms and to predict the possible products, not to model one (or each) specific mass spectrometer.

\section{Single vs multiple collisions}

CID is not at all limited to triple-quadrupole instruments and to the single collision limit. Ion traps are largely employed in mass spectrometry, in particular for large molecules. One key difference is that in ion traps, the fragmentation results from multiple low energy collision events. Figure 8 gives a graphical representation of the two activation modes for the model case of a 
fragmenting Morse oscillator. In the case of ion trap like activation, we assume that after each collision the energy is totally randomized between the modes before the next collision occurs. This corresponds to random activation of the different modes (i.e. statistical distribution of the excess energy). It is modeled by selecting initial conditions for the ion from a microcanonical ensemble at the given total energy, $E$. As discussed below, for a large molecule a temperature $T$ may be associated with $E$ and this becomes a thermal activation method. ${ }^{146}$ It was recently applied to fragmentation of a doubly charged tripeptide $[\mathrm{TIK}+2 \mathrm{H}]^{2+}{ }^{146,185}$ and diproline anion $\left(\left[\mathrm{Pro}_{2}-\mathrm{H}\right]^{-}\right.$ ). ${ }^{173,186}$ Fragments were obtained and compared with collisional simulations in terms of their nature and the corresponding mechanisms. For example, we observed that side chain fragments are more abundant in single collision simulations than in internal energy activation simulations.

By using statistical mechanics, the (vibrational) internal energy of a set of classical harmonic oscillators can be related to the (vibrational) temperature via the simple relation ${ }^{187}$

$E=s k_{B} T$

in which $s$ is the number of normal modes, $k_{B}$ the Boltzmann constant, and $T$ the temperature. This expression holds for fragmentation simulations presented here since the equations of motions are propagated using classical physics, and it is valid when quantum nuclear effects can be disregarded.

If the unimolecular dynamics of the randomly excited ion energy $E$ is ergodic, its decay will be exponential and a rate constant, $k(E)$, may be determined from exponential decay. This is a classical unimolecular rate constant, and does not include quantum effects such as tunneling and zero-point energy constraints. As shown previously, ${ }^{188}$ if $s \approx(s-1)$ for the unimolecular reactant's $s$ vibrational modes and the unimolecular dissociation energy $E_{o}$ is much less than the reactant's energy $E$ (i.e. $E_{o} / E \ll 1$ ), the classical microcanonical RRKM unimolecular rate constant $k(E)$ at $E$ becomes identical to the classical canonical transition state theory (TST) rate constant $k(T)$ at $T$ with $E=s k_{B} T,{ }^{187}$ where $k_{B}$ is the Boltzmann constant. Thus, constant $E$ simulations may be used to determine rate constants for constant $T$. This relation between $E$ and $T$ has also been discussed with respect to product energies in unimolecular dissociation. ${ }^{118}$

By performing simulations at different $E$, the rate constant $k(T)$ may be obtained at different $T$. Verifying Arrhenius behavior, 
$k(T)=A e^{-\frac{E_{a}}{k_{B} T}}$

it is possible to obtain the pre-exponential factor and activation energy for the total unimolecular dissociation. Rate constants for individual pathways, $k_{i}(T)$, can be obtained from $k(T)$, for which the individual $k_{i}(T)$ equals $k(T)$ multiplied by the number of dissociations for the $i^{\text {th }}$ pathway divided by the total number of dissociations $p_{i}(T)$; that is, $k_{i}(T)=p_{i}(T) k(T)$. Thus, pre-exponential factors and activation energies may be determined for individual pathways. The activation energy $E_{a}$ equals the classical potential energy barrier for the unimolecular dissociation. ${ }^{146}$

The constraints $s \approx(s-1)$ and $E_{o} / E \ll 1$ apply to $[\mathrm{TIK}+2 \mathrm{H}]^{2+}$ and $\left[\mathrm{Pro}_{2}-\mathrm{H}\right]^{-}$dissociation and the above approach was used to determine pre-exponential factors and activation energies for some of their dissociation pathways. ${ }^{146,186}$ This analysis was possible for pathways that had statistically meaningful values of $p_{i}(T)$. Within statistical uncertainties, the resulting activation energies were in agreement with barrier heights of transition states located as saddle points. ${ }^{146,186}$ This opens the possibility of using simulations to directly locate energy thresholds and, as we discuss in section IV, use them to extrapolate results to longer times. Of course, statistically meaningful values of $k_{i}(T)$ will be obtained mainly for the important pathways, which will have lower activation energies and faster kinetics. To better describe slower and rare events, with this direct approach, a larger number of longer trajectories will be necessary. For large biological ions, the constraint $s \approx(s-$ 1) will always apply. Also, given the large value for $s$, it is expected that the constraint $E_{o} / E \ll 1$ will also be applicable, but it should always be tested.

\section{E. Methods performances}

The accuracy and reliability of the simulations can be established either by comparing results with experimental data or with other calculations. In previous sections, we have discussed how simulation results compare with experiments and which factors must be taken into account for a correct comparison. In particular, we should point out that simulations are limited in timelength such that fast processes are necessarily overestimated: this means that often secondary fragmentations are not sampled.

Another possibility is to compare different theoretical methods (i.e. dynamics done using different quantum chemistry methods to describe the reactivity). This is particularly important when using semi-empirical Hamiltonians. When the size of the system allows, as for uracil and NFormylalanylamide, we have compared AM1 and PM3 results with density functional theory 
(DFT) results using the B3LYP functional. ${ }^{141,169}$ Results show that semi-empirical Hamiltonians provide globally the same products. In general, fewer DFT-trajectories are performed and have a reduced simulation time with respect to those done with semi-empirical Hamiltonians and thus results are not fully converged, statistically speaking. Finally, in the case of TIK we compared AM1 and RM1 results, finding the same fragmentation patterns. ${ }^{146}$

Concluding, the choice of semi-empirical method is based on the one hand on the practical implementation of the coupling between VENUS and the semi-empirical package, and on the other hand on the performances of the method. RM1 and PM6-D are suggested as good first choice to perform fragmentation simulations. In the future, a systematic assessment of semi-empirical methods (including also the tight-binding $\mathrm{DFT}^{189}$ ) will surely be useful to provide a clear guide to choose the best method for the given system.

\section{Future Directions}

There are a number of future directions for the research described in this work. It should be possible to use the information provided by experiments regarding the time dependence of ion formation to predict the ion yield at longer times. For small biological ions, it may be possible to use quantum dynamics to simulate their fragmentation. It would also be of interest to develop software for including a zero-point energy (ZPE) constraint in the classical dynamics simulations

of fragmentation. ${ }^{189-192}$ Proton transfer along a peptide ion's backbone is important for fragmentation, and rate constants may be determined from the simulations. Finally, there are a number of important simulations of biological molecules colliding with surfaces and of their CID to be performed, which are extensions of the previous studies, but require enhancements of the computational methodology.

\section{A. Extrapolating the Fragmentation Dynamics to Long Times}

One interesting future direction will be to use rate constants obtained from the simulations to extrapolate results to longer times. In particular, as shown for primary fragmentations, ${ }^{146,193}$ it is possible to follow the formation in time of different products and fit their abundance with a kinetic model. For unimolecular irreversible fragmentations, a simple model would consist of an initial ion fragmenting into $n$ primary products which can eventually further fragment into $m$ secondary products. The number of primary products and subsequent branching reactions will depend on specific rate constants. Each fragmentation step is characterized by a rate constant 
which can be obtained as shown in section III.D directly from simulations, avoiding the procedure of locating the TSs. Then, the full kinetic systems can be solved analytically or numerically. By extrapolating the ratio of different ions to longer times, it may be possible to obtain a timeindependent theoretical mass spectrum which will reflect theoretical ion ratios on time-scales closer to the experimental ones. This may overcome the problem arising from limitation in simulation time. In fact, one limitation of simulations is that short time-scale products are normally overestimated. If at least some low abundance products are obtained, then their rate constants can be fitted from trajectories and their abundance at longer time-scales estimated. Of course, the quality of the estimation will depend on the abundance of such rare events, and likely more trajectories with longer simulation times will be necessary. Furthermore, by fitting Arrhenius-like or RRKM expressions with rate constants obtained from simulations, it will be in principle possible to use such information in more specific models of fragmentation of ions as those specifically conceive by Knyazev and Stein for double-octopole guided beam, triple-quadrupole and quadrupole-hexapole-quadrupole tandem mass spectrometers. ${ }^{147,194}$

\section{B. Quantum Dynamics}

The chemical dynamics simulations described above for SID and CID use classical mechanics for the atomistic dynamics. For some particular conditions, nuclear quantum effects may be important. One may be concerned with tunneling for proton transfer reactions and zeropoint energy effects for ion fragmentations. In recent years, different methods have been developed for using classical trajectories to account for quantum effects. ${ }^{190-192,195-197}$ Wave-packet methods, even with efficient approaches like multi-configuration time-dependent Hartree, ${ }^{198}$ are too computationally demanding for application to SID and CID systems, and this is expected to be the case for the near future. However, methods like Centroid Molecular Dynamics, ${ }^{199}$ Ring Polymer Molecular Dynamics, ${ }^{200}$ and Quantum Thermal Bath ${ }^{201}$ may be applicable. This will require implementations and accurate studies to evaluate the feasibility of their applications. A first application of Quantum Thermal Bath was reported by Spezia and Hammak for the model reaction $\mathrm{CH}_{4} \rightarrow \mathrm{CH}_{3}+\mathrm{H}^{202}$ These methods are defined for canonical ensembles and will need some reformulation and/or ad hoc modification to study collisions. The use of semi-classical methods, which may be defined for microcanonical ensembles, is tempting. While rigorous methods like Herman-Kluck ${ }^{203}$ are computationally intractable for CID and SID, more approximate methods, like frozen Gaussians ${ }^{204}$ or generalized Gaussian wave-packet ${ }^{205}$ dynamics, are probably 
affordable. Future studies, incorporating quantum dynamics will be surely useful, not only for SID and CID, but in general for understanding gas phase ion reaction dynamics.

\section{ZPE Constraint for Fragmentation}

In classical chemical dynamics simulations, a fragmentation transition state (TS) may be crossed without ZPE in the vibrational modes orthogonal to the reaction coordinate, which results in lower threshold for fragmentation than that given by quantum dynamics. As a result, the classical fragmentation rate constant is larger than the quantum value. A ZPE constraint has been proposed for providing a correction to the classical dynamics, ${ }^{191}$ resulting in the quantum threshold and a rate constant closer to the quantum value. For a fragmentation without a saddle point, as for ${ }^{+} \mathrm{NH}_{3} \mathrm{CH}_{2}-\mathrm{COOH} \rightarrow \mathrm{NH}_{3} \mathrm{CH}_{2}{ }^{+}+\mathrm{COOH}$, if each fragment has an internal energy which is less than the ZPE the velocities of the atoms are reversed and the trajectory returned to the reactant region of phase space. In this manner, the classical simulations have the quantum threshold. This procedure is continued until fragments are formed with ZPE and the reactant's lifetime is the total trajectory time for forming fragments with ZPE.

The above algorithm needs to be extended so that it may be applied to a TS at a saddle point, for which the requirement would be ZPE in the vibration modes orthogonal to the TS's reaction coordinate. The algorithm and software need to be developed for implementing this procedure into the classical chemical dynamics simulations. For the above bond dissociation reaction, without a saddle point, a sufficient ZPE constraint is ZPE in each fragment.

\section{Determining $k(T)$ for Proton Transfer}

An important component of the dynamics of peptide ion fragmentation is proton transfer along the its backbone. Knowledge of the rate constants $k(T)$, for these transfers, would be very helpful in modeling the ion's fragmentation. The same procedure, as used to study peptide- $\mathrm{H}^{+}$ fragmentation versus temperature, ${ }^{146,186}$ may be used to determine $k(T)$ for proton transfer. The ion may be thermally excited with $\mathrm{H}^{+}$attached to different sites, e.g. $\mathrm{NH}_{2}, \mathrm{COOH}$, and the C-N peptide bond, and $k(T)$ determined for proton transfer. If multiple transfers occur, $k(T)$ may be determined for each individual transfer. Arrhenius parameters, $A$ and $E_{a}$, may be determined from the $k(T)$. $E_{a}$ is the classical activation energy without ZPE, but it should be straightforward to develop models for including a ZPE correction.

\section{E. Future CID and SID Simulations}


Finally, after the series of successful studies on CID of organic and small biological molecules as amino-acids, peptides or sugars with less than 100 atoms, as described above, an important step will be to simulate larger systems, like extended polypeptides, sugars, DNA etc ... Towards this end, the electronic structure description must be greatly simplified to speed-up the calculations. Even semi-empirical Hamiltonians will be too computationally demanding for an appropriate statistical sampling. Analytical force fields, which describe the fragmentation dynamics, should be developed in order to study larger molecules and make the CID simulations applicable to proteomics, glycomics, and metabolomics. Data bases for the force fields could be constructed by direct dynamics simulations of the pathways for smaller molecules. A possibility to develop analytical potential for chemical reactivity will be using "machine learning" techniques. $^{206-208}$

An interesting future extension of the simulation method will concern the reactivity of complexes with transition metals. ${ }^{209,210}$ In this case, a careful description of the potential energy surface is needed, with the likelihood of spin transitions also considered. The possibility of using modern DFT methods or further developments of electronic structure theory methods is appealing. At the present time, such simulations are limited by the computing time and by the difficulty of obtaining a reasonable description of the potential energy surface with methods not too computationally demanding. Studies in this direction are surely welcome.

For simulations of collisions of biological ions with surfaces, there is a need for additional studies of soft-landing and reactive-landing for comparison with experiment. To simulate collisions of large biological ions with surface, analytic potentials are needed and a strategy for their construction follow the above scheme described for the CID simulations. There is a considerable interest in simulating collisions of peptide dimers composed by units with different charge states. If there is prompt SID fragmentation of the dimer, there may not be extensive proton transfer between the different peptides with a considerable effect on final products. The SID fragmentation may be compared with random thermal excitation fragmentation and it would be instructive to understand how the two eventually differ.

\section{Acknowledgements}

Riccardo Spezia and William L. Hase thank ANR DynBioReact (Grant No. ANR-14CE06-0029-01), the National Science Foundation under Grant No. CHE-1416428, and the Robert 
A. Welch Foundation under Grant No. D-0005 for support. George L. Barnes gratefully acknowledges support from the National Science Foundation under Grant No. 1763652. Li Yang thanks the support from the National Natural Science Foundation of China (Grant No. 21403047). The authors wish to thank Emilio Martínez-Núñez, Tim Minton, John Morris, Gil Nathanson, David Nesbitt, George Schatz, Steve Sibener, John Tully, and Alec Wodtke for important insights concerning the non-thermal dynamics of gas-surface collisions resulting in physisorption and chemisorption.

\section{References}

1. Cooks, R.G., Ast, T., Pradeep, T., Wysocki, V.: Reactions of Ions with Organic Surfaces. Acc. Chem. Res. 27, 316-323 (1994)

2. McLuckey, S.A., Goeringer, D.E.: Slow Heating Methods in Tandem Mass Spectrometry. J. Mass Spectrom. 32, 461-474 (1997)

3. Shukla, A.K., Futrell, J.H.: Tandem Mass Spectrometry: Dissociation of Ions by Collisional Activation. J. Mass Spectrom. 35, 1069-1090 (2000)

4. Williams, E.R.; Tandem FTMS of Large Biomolecules. Anal. Chem. 70, 179A-185A (1998)

5. Gologan, B., Green, J.R., Alvarez, J., Laskin, J., Cooks, R.G.: Ion/Surface Reactions and SoftLanding. Phys. Chem. Chem. Phys. 7, 1490-1500 (2005)

6. Wysocki, V.H., Joyce, K.E., Jones, C.M., Beardsley,R L.: Surface-Induced Dissociation of Small Molecules, Peptides, and Non-Covalent Protein Complexes. J. Am. Soc. Mass Spectrom. 19, 190-208 (2008)

7. Papayannopoulos, I.A.: The Interpretation of Collision-Induced Dissociation Tandem Mass Spectra of Peptides. Mass Spectrom. Rev. 14, 49-73 (1995)

8. Zaia, J.: Mass Spectrometry of Oligosaccharides. Mass Spectrom. Rev. 23, 161-227 (2004) 
9. Paisz, B., Suhai, S.: Fragmentation Pathways of Protonated Peptides. Mass Spectrom. Rev. 24, 508-548 (2005)

10. Laskin, J., Futrell, J.H.: Collisional Activation of Peptide Ions in FT-ICR Mass Spectrometry. Mass. Spectrom. Rev. 22, 158-181 (2003)

11. Fenn, J. B., Mann, M., Meng, C.K., Wong, S.F., Whitehouse, C.M.: Electrospray Ionization for Mass Spectrometry of Large Biomolecules. Science 246, 64-71 (1989)

12. Mabud, M.D.A., Dekrey, M.J., Cooks, R.G.: Surface-Induced Dissociation of Molecular Ions. Int. J. Mass Spectrom. Ion Process. 67, 285-294 (1985)

13. Dongre, A.R., Somogyi, A., Wysocki, V.H.: Surface-Induced Dissociation: An Effective Tool to Probe Structure, Energetics and Fragmentation Mechanisms of Protonated Peptides. J. Mass Spectrom. 31, 339-350 (1996)

14. Franchetti, V., Solka, B.H., Baitinger, W.E., Amy, J.W., Cooks, R.: G. Soft Landing of Ions as a Means of Surface Modification. Int. J. Mass Spectrom. Ion Phys. 23, 29-35 (1977)

15. Miller, S.A., Luo, H., Pachuta, S.J., Cooks, R.G.: Soft-Landing of Polyatomic Ions at Fluorinated Self-Assembled Monolayer Surfaces. Science 275, 1447-1450 (1997)

16. Shen, J.W., Evans, C., Wade, N., Cooks, R.G.: Ion-Ion Collisions Leading to Formation of CC Bonds at Surfaces: An Interfacial Kolbe Reaction. J. Am. Chem. Soc. 121, 9762-9763 (1999)

17. Kolasinski, K.: Surface Science Foundations of Catalysis and Nanoscience, Wiley (2002)

18. Rettner, C.T., Pfnür, H.E., Auerbach, D. J.: Dissociative Chemisorption of $\mathrm{CH}_{4}$ on W(110): Dramatic Activation by Initial Kinetic Energy. Phys. Rev. Lett. 54, 2716 (1985).

19. Chadwick, H., Guo, H., Gutiérrez-González, A., Menzel, J.P., Jackson, B., Beck, R.D.: Methane Dissociation on the Steps and Terraces of Pt(211) Resolved by Quantum State and Impact Site. J. Chem. Phys. 148, 014701 (2018)

20. Gibson, K.D., Killelea, D.R., Yuan, H., Becker, J.S., Sibener, S. J.: Determination of the Sticking Coefficient and Scattering Dynamics of Water on Ice Using Molecular Beam Techniques. J. Chem. Phys. 134, 034703 (2011).

21. Lu, J. W., Day, B. S., Fiegland, L.R., Davis, E.D., Alexander, W.A., Troya, D., Morris, J.R.: Interfacial Energy Exchange and Reaction Dynamics in Collisions of Gases on Model Organic Surfaces. Prog. Surf. Sci. 87, 221-252 (2012) 
22. Kumar, S., Jiang, H., Schwarzer, M., Kandratsenka, A., Schwarzer, D., Wodtke, A.M.: Vibrational Relaxation Lifetime of a Physisorbed Molecule at a Metal Surface. Phys. Rev. Lett., 123, 156101 (2019)

23. Saecker, M.E., Nathanson, G.M.: Collisions of Protic and Aprotic Gases with Hydrogen Bonding and Hydrocarbon Liquids. J. Chem. Phys. 99, 7056-7075 (1993)

24. Yan, T.-Y., Hase, W.L., Barker, J.R.: Identifying Trapping Desorption in Gas-Surface Scattering. Chem. Phys. Lett. 329, 84-91 (2000)

25. Nogueira, J., Vazquez, S., Mazyar, O., Hase, W.L., Perkins, B., Nesbitt, D., Martínez-Núñez, E.: Dynamics of $\mathrm{CO}_{2}$ Scattering off a Perfluorinated Self-Assembled Monolayer. Influence of the Incident Collision Energy, Mass Effects, and Use of Different Surface Models. J. Phys. Chem. A $113,3850-3865$ (2009)

26. Gologan, B., Takats, Z., Alvarez, J., Wiseman, J.M., Talaty, N., Ouyang, Z., Cooks, R.G.: Ion Soft-Landing into Liquids: Protein Identification, Separation, and Purification with Retention of Biological Activity. J. Am. Soc. Mass Spectrom. 15, 1874-1884 (2004)

27. Blake, T.A., Ouyang, Z., Wiseman, J.M., Takáts, Z., Guymon, A.J., Kothari, S., Cooks, R.G.: Preparative Linear Ion Trap Mass Spectrometer for Separation and Collection of Purified Proteins and Peptides in Arrays Using Ion Soft Landing. Anal. Chem. 76,6293-6305 (2004)

28. Wang, P., Laskin, J.: Helical Peptide Arrays on Self-Assembled Monolayer Surfaces through Soft and Reactive Landing of Mass-Selected Ions. Angew. Chem., Int. Ed. 47, 6678-6680 (2008) 29. Ouyang, Z., Takats, Z., Blake, T.A., Gologan, B., Guymon, A.J., Wiseman, J.M., Oliver, J.C., Davisson, V.J., Cooks, R.G.: Preparing Protein Microarrays by Soft-Landing of Mass-Selected Ions. Science 301, 1351-1354 (2003)

30. Wang, P., Hadjar, O., Laskin, J.: Covalent Immobilization of Peptides on Self-Assembled Monolayer Surfaces Using Soft-Landing of Mass-Selected Ions. J. Am. Chem. Soc. 129, 86828683 (2007)

31. Volny, M., Elam, W.T., Ratner, B.D., Turecek, F.: Enhanced in-Vitro Blood Compatibility of 3161 Stainless Steel Surfaces by Reactive Landing of Hyaluronan Ions. J. Biomed. Mater. Res., Part B 80B, 505-510 (2007)

32. Heiz, U., Bullock, E.L.: Fundamental Aspects of Catalysis on Supported Metal Clusters. J. Mater. Chem. 14, 564-577 (2004)

33. Bittner, A.M.: Clusters on Soft Matter Surfaces. Surf. Sci. Rep. 61, 383-428 (2006) 
34. Popok, V.N., Barke, I., Campbell, E.E.B., Meiwes-Broer, K.H.: Cluster-Surface Interaction: From Soft Landing to Implantation. Surf. Sci. Rep. 66, 347-377 (2011)

35. Kahle, S., Deng, Z.T., Malinowski, N., Tonnoir, C., Forment-Aliaga, A., Thontasen, N., Rinke, G., Le, D., Turkowski, V., Rahman, T.S., Rauschenbach, S., Ternes, M., Kern, K.: The Quantum Magnetism of Individual Manganese-12-Acetate Molecular Magnets Anchored at Surfaces. Nano Lett. 12, 518-521 (2012)

36. Rauschenbach, S., Rinke, G., Malinowski, N., Weitz, R.T., Dinnebier, R., Thontasen, N., Deng, Z.T., Lutz, T., Rollo, P.M.D.A., Costantini, G., Harnau, L., Kern, K.: Crystalline Inverted Membranes Grown on Surfaces by Electrospray Ion Beam Deposition in Vacuum. Adv. Mater. 24, 2761-2767 (2012)

37. Palmer, R.E., Pratontep, S., Boyen, H. G.: Nanostructured Surfaces from Size-Selected Clusters. Nat. Mater. 2, 443-448 (2003)

38. Vajda, S., Winans, R.E., Elam, J.W., Lee, B.D., Pellin, M.J., Seifert, S., Tikhonov, G.Y., Tomczyk, N.A.: Supported Gold Clusters and Cluster-Based Nanomaterials: Characterization, Stability and Growth Studies by in Situ Gisaxs under Vacuum Conditions and in the Presence of Hydrogen. Top. Catal. 39, 161-166 (2006)

39. Roepstroff P., Fohlman, J.: Proposal for a Common Nomenclature for Sequence Ions in Mass Spectra of Peptides. Biomed. Mass Spectrom. 11, 601 (1984)

40. Chen, X., Yu, L., Steill, J., Oomens, J., Polfer, N.C.: Effect of Peptide Fragment Size on the Propensity of Cyclization in Collision-Induced Dissociation: Oligoglycine $b_{2}-b_{8}$. J. Am. Chem. Soc. 131, 18272-18282 (2009)

41. Huang, Y., Triscari, J.M., Tseng, G.C., Pasa-Tolic, L., Lipton, M.S., Smith, R.D., Wysocki, V.H.: Statistical Characterization of the Charge State and Residue Dependence of Low-Energy CID Peptide Dissociation Patterns. Anal. Chem. 77, 5800-5813 (2005)

42. Bythell, B.J., Maître, Ph., Paizs, B.: Cyclization and Rearrangement Reactions of $a_{n}$ Fragment Ions of Protonated Peptides. J. Am. Chem. Soc. 132, 14766-14779 (2010)

43. Yalcin, T., Khouw, C., Csizmadia, I.G., Peterson, M.R., Harrison, A.G.: Why Are B Ions Stable Species in Peptide Spectra? J. Am. Soc. Mass Spectrom. 6, 1164-1174 (1995)

44. Savitski, M.M, Fälth, M., Fung, Y.M.E., Adams, C.M., Zubarev, R.A.: Bifurcating Fragmentation Behavior of Gas-Phase Tryptic Peptide Dications in Collisional Activation. J. Am. Soc. Mass Spectrom. 19, 1755-1763 (2008) 
45. Yalcin, T., Csizmadia, I.G., Peterson, M.R., Harrison A.G.: The Structure and Fragmentation of $B_{n}(n \geq 3)$ Ions in Peptide Spectra. J. Am. Soc. Mass Spectrom. 7, 233-242 (1996)

46. Gross, J.H.: Mass Spectrometry. A Textbook. Springer, Berlin (2004)

47. Bythell, B.J., Erlekam, U., Paizs, B., Maître, Ph.: Infrared Spectroscopy of Fragments from Doubly Protonated Tryptic Peptides. ChemPhysChem 10, 883-885 (2009)

48. Scuderi, D., Bodo, E., Chiavarino, B., Fornarini, S., Crestoni, M.E.: Amino-Acids Oxidation: A Combined Study of Cysteine Oxo-Forms by IRMPD Spectroscopy and Simulation. Chem. Eur. J. 22, 17239-17250 (2016)

49. Polfer, N.C., Oomens, J., Suhai, S., Paizs, B.: Spectroscopic and Theoretical Evidence for Oxazolone Ring Formation in Collision-Induced Dissociation of Peptides. J. Am. Chem. Soc. 127, 17154-17155 (2005)

50. Grzetic, J., Oomens, J.: Spectroscopic Identification of Cyclic Imide $b_{2}$-Ions from Peptides Containing Gln and Asn Residues. J. Am. Soc. Mass Spectrom. 24, 1228-1241 (2013)

51. Kempkes, L.J.M., Martens, J., Grzetic, J., Berden, G., Oomens. J.: J. Am. Soc. Mass Spectrom. 27, 1855-1869 (2016)

52. Grzetic, J., Oomens, J.: Spectroscopic Evidence for an Oxazolone Structure in Anionic b-Type Peptide Fragments. J. Am. Soc. Mass Spectrom. 23, 290-300 (2012)

53. Polfer, N.C., Oomens, J.: Vibrational Spectroscopy of Bare and Solvated Ionic Complexes of Biological Relevance. Mass Spectrom. Rev. 28, 468-494 (2009)

54. Kellersberger, K.A., Yu, E., Kruppa, G.H., Young, M.M., Fabris, D.: Top-down Characterization of Nucleic Acids Modified by Structural Probes Using High-Resolution Tandem Mass Spectrometry and Automated Data Interpretation. Anal. Chem. 76, 2438-2445 (2004)

55. Huang, T.-y., Kharlamova, A., McLuckey, S.A.: Ion Trap Collision-Induced Dissociation of Locked Nuclei Acids. J. Am. Soc. Mass Spectrom. 21, 144-153 (2010)

56. Farand, J., Gosselin, F.: De Novo Sequence Determination of Modified Oligonucleotides. Anal. Chem. 81, 3723-3730 (2009)

57. McLuckey, S.A., Habibigoudarzi, S.: Ion-Trap Tandem Mass Spectrometry Applied to Small Multiply-Charged Oligonucleotides with a Modified Base. J. Am. Soc. Mass Spectrom. 5, 740747 (1994) 
58. Tromp, J. M., Schürch, S.: Gas-Phase Dissociation of Oligoribonucleotides and their Analogues Studied by Electrospray Ionization Tandem Mass Spectrometry. J. Am. Soc. Mass Spectrom. 16, 1262-1268 (2005)

59. Poyer, S., Lopin-Bon, C., Jacquinet, J-C., Salpin, J.-Y., Daniel, R.: Isomer Separation and Effect of the Polymerization Degree on the Gas-Phase Structure of Chondroitin Sulfate Oligosaccharides Analyzed by Ion Mobility-Tandem Mass Spectrometry. Rapid Comm. Mass Spectrom. 31, 2003-2010 (2017)

60. Domon, B., Costello, C.E.: A Systematic Nomenclature for Carbohydrate Fragmentations in FAB-MS/MS Spectra of Glycoconjugates. Glycoconjugate J. 5, 397-409 (1988)

61. Gaye, M.M., Kurulugama, R., Clemmer, D.E.: Investigating Carbohydrate Isomers by IMSCID-IMS-MS: Precursor and Fragment Ion Cross-Sections. Analyst. 140, 6922-6932 (2015)

62. Saad, O.M., Leary, J.A.: Delineating Mechanisms of Dissociation for Isomeric Heparin Disaccharides Using Isotope Labeling and Ion Trap Tandem Mass Spectrometry. J. Am. Soc. Mass Spectrom. 15, 1274-1286 (2004).

63. Bythell, B.J., Abutokaikah, M.T., Wagoner, A.R., Guan, S., Rabus, J.M.: Cationized Carbohydrate Gas-Phase Fragmentation Chemistry. J. Am. Soc. Mass Spectrom. 28, 688-703 (2017)

64. Suzuki, H., Kameyama, A., Tachibana, K., Narimatsu, H., Fukui, K.: Computationally and Experimentally Derived General Rules for Fragmentation of Various Glycosyl Bonds in Sodium Adduct Oligosaccharides. Anal. Chem. 81, 1108-1120 (2009)

65. Yamagaki, T., Fukui, K., Tachibana, K.: Analysis of Glycosyl Bond Cleavage and Related Isotope Effects in Collision-Induced Dissociation Quadrupole-Time-of-Flight Mass Spectrometry of Isomeric Trehaloses. Anal. Chem. 78, 1015-1022 (2006)

66. Han, X., Aslanian, A., Yates, J.R.III: Mass Spectrometry for Proteomics. Curr. Op. Chem. Biol. 12, 483-490 (2008)

67. McLafferty, F.W., Breuker, K., Ji, M., Han, X., Infusini, G., Jiang, H., Kong, X., Begley, T.P.: Top-down MS, a Powerful Complement to the High Capabilities of Proteolysis Proteomics. FEBS 274, 6256-6268 (2007)

68. Jensen, O.N.: Modification-Specific Proteomics: Characterization of Post-Translational Modifications by Mass Spectrometry. Curr. Op. Chem. Biol. 8, 33-41 (2004) 
69. Xiao, J.F., Zhou, B., Ressom, H.W.: Metabolite Identification and Quantitation in LC-MS/MSbased Metabolomics. Trends Anal. Chem. 32, 1-14 (2012)

70. Reese, K.L., Jones, A.D., Smith, R.W.: Characterization of Smokeless Powders Using Multiplexed Collision-Induced Dissociation Mass Spectrometry and Chemometric Procedures. Forensic Sci. Int. 272, 16-27 (2017)

71. Touber, M.E., van Engelen, M.C., Georgakopoulos, C., van Rhijn, J.A., Nielen, M.W.: MultiDetection of Corticosteroids in Sports Doping and Veterinary Control Using High-Resolution Liquid Chromatography/Time-of-Flight Mass Spectrometry. Anal. Chim. Acta. 586, 137-146 (2007)

72. S. Pratihar, S., Barnes, G.L., Hase, W.L.: Chemical Dynamics Simulations of Energy Transfer, Surface-Induced Dissociation, Soft-Landing, and Reactive-Landing in Collisions of Protonated Peptide Ions with Organic Surfaces. Chem. Soc. Rev. 45, 3595-3608 (2016)

73. Pratihar, S., Barnes, G.L., Laskin, J., Hase, W.L.: Perspective: Dynamics of Protonated Peptide Ion Collisions with Organic Surfaces. Consonance of Simulation and Experiment. J. Phys. Chem. Lett. 7, 3142-3150 (2016)

74. Schultz, D.G., Weinhaus, S.B., Hanley, L., de Sainte Claire, P., Hase, W. L.: Classical Dynamics Simulations of $\mathrm{SiMe}_{3}{ }^{+}$Ion-Surface Scattering. J. Chem. Phys. 106, 10337-10348 (1997) 75. Bosio, S.B.M., Hase, W.L.: Simulations of Energy Transfer in $\mathrm{Cr}(\mathrm{CO})_{6}{ }^{+}$Surface Induced Dissociation. Int. J. Mass Spectrom. Ion Process. 174, 1-9 (1998)

76. Meroueh, O., Hase, W.L.: Effect of Surface Stiffness on the Efficiency of Surface-Induced Dissociation. Phys. Chem. Chem. Phys. 3, 2306-2314 (2001)

77. Song, K., Meroueh, O., Hase, W.L.: Dynamics of $\mathrm{Cr}(\mathrm{CO})_{6}{ }^{+}$Collisions with Hydrogenated Surfaces. J. Chem. Phys. 118, 2893-2902 (2003)

78. Morris, M.R., Riederer, D.E. Jr., Winger, B.E., Cooks, R.G., Ast,T., Chidsey, C.E.D.: Ion/Surface Collisions at Functionalized Self-Assembled Monolayer Surfaces. Int. J. Mass Spectrom. Ion Process. 122, 181-217 (1992)

79. Burroughs, J.A., Wainhaus, S.B., Hanley, L.: Impulsive Dissociation of $\mathrm{Cr}(\mathrm{CO})_{6}{ }^{+}$during Surface-Induced Dissociation at Organic Surfaces. J. Phys. Chem. 98, 10913-10919 (1994)

80. Weinhaus, S.B., Lim, H., Schultz, D.G., Hanley, L.: Energy Transfer and Surface-Induced Dissociation for $\mathrm{SiMe}_{3}{ }^{+}$Scattering off Clean and Adsorbate Covered Metals. J. Chem. Phys. 106, 10329-10336 (1997) 
81. Cornell W.D., Cieplak, P., Bayly, C.I., Gould, I.R., Merz, K.M. Jr., Ferguson, D.M., Spellmeyer, D.C., Fox, T., Caldwell, J.W., Kollman, P.A.: A Second Generation Force Field for the Simulation of Proteins, Nucleic Acids, and Organic Molecules. J. Am. Chem. Soc. 117, 5179$5197(1995)$

82. Dewar, M.J.S., Zoebisch, E.G., Healy, E.F., Stewart, J.J.P.: Development and Use of Quantum Mechanical Molecular Models. 76. AM1: A New General Purpose Quantum Mechanical Molecular Model. J. Am. Chem. Soc. 107, 3902-3909 (1985)

83. Head-Gordon, M., Pople, J.A., Frisch, M.J.: MP2 Energy Evaluation by Direct Methods. Chem. Phys. Lett. 153, 503-506 (1988)

84. Sun, L., Hase, W.L.: Born-Oppenheimer Direct Dynamics Classical Trajectory Simulations. Rev. Comput. Chem. 19, 79-146 (2003)

85. Mar, W., Klein, M.: Molecular Dynamics Study of the Self-Assembled Monolayer Composed of $\mathrm{S}\left(\mathrm{CH}_{2}\right){ }_{14} \mathrm{CH}_{3}$ Molecules Using an All-Atoms Model. Langmuir 10, 188-196 (1994)

86. Hass, K.C., Tamor, M.A., Anthony, T.R., Banholzer, W.F.: Lattice dynamics and Raman spectra of isotopically mixed diamond. Phys. Rev. B 45, 7171 (1992)

87. Borodin, O., Smith, G.D., Bedrov, D.: A Quantum Chemistry Based Force Field for Perfluoroalkanes and Poly(tetrafluoroethylene). J. Phys. Chem. B 106, 9912-9922 (2002)

88. Meroueh, O., Hase, W.L.: Collisional Activation of Small Peptides. J. Phys. Chem. A 103, 3981-3990 (1999)

89. Mackerell, A.D. Jr., Feig, M., Brooks, C.L. III: Extending the Treatment of Backbone Energetics in Protein Force Fields: Limitations of Gas-Phase Quantum Mechanics in Reproducing Protein Conformational Distributions in Molecular Dynamics Simulations. J. Comput. Chem. 25, 1400-1415 (2004)

90. Watkins, E.K., Jorgensen, W.L.: Perfluoroalkanes: Conformational Analysis and Liquid -State Properties from Ab Initio and Monte Carlo Calculations. J. Phys. Chem. A 105, 4118-4125 (2001) 91. Deb, B., Hu, W., Song, K., Hase, W.L.: An analytical Potential Energy Function to Model Protonated Peptide Soft-Landing Experiments. The $\mathrm{CH}_{3} \mathrm{NH}_{3}{ }^{+} / \mathrm{CH}_{4}$ Interactions. Phys. Chem. Chem. Phys. 10, 4565-4572 (2008)

92. Pratihar S., Kohale, S.C., Vázquez, S.A., Hase, W.L.: Intermolecular Potential for Binding of Protonated Peptide Ions with Perfluorinated Hydrocarbon Surfaces. J. Phys. Chem. B 118, 55775588 (2014) 
93. Mahan, B.H.: Refined Impulse Approximation for the Collisional Excitation of the Classical Anharmonic Oscillator. J. Chem. Phys. 52, 5221-5225 (1970)

94. de Sainte Claire, P., Hase, W.L.: Thresholds for the Collision-Induced Dissociation of Clusters by Rare Gas Impact. J. Phys. Chem. 100, 8190-8196 (1996)

95. Meroueh, O., Hase, W.L.: Dynamics of Energy Transfer in Peptide-Surface Collisions. J. Am. Chem. Soc. 124, 1524-1531 (2002)

96. Wang, J., Hase, W.L.: An Intermolecular Potential to Represent Collisions of Protonated Peptide Ions with Fluorinated Alkane Surfaces. J. Phys. Chem. B 109, 8320-8324 (2005)

97. Peslherbe, G.H., Wang, H., Hase, W.L.: Monte Carlo Sampling for Classical Trajectory Simulations. Adv. Chem. Phys. 105, 171-201 (1999)

98. de Maaijer-Gielbert, J., Somogyi, Á., Wysocki, V.H., Kisemaker, P.G., Weeding, T.L.: Surface-induced dissociation of diphenyl ether Int. J. Mass Spectrom. 174, 81-94 (1998)

99. Vékey, K., Somogyi, Á., Wysocki, V.H.: Internal Energy Distribution of Benzene MolecularIons in Surface-Induced Dissociation. J. Mass Spectrom. 30, 212-217 (1995)

100. Laskin, J., Denisov, E., Futrell, J.H.: Comparative Study of Collision-Induced and SurfaceInduced Dissociation. 1. Fragmentation of Protonated Dialanine. J. Am. Chem. Soc. 122, 97039714 (2000)

101. Laskin, J., Futrell, J.H.: Energy Transfer in Collisions of Peptide Ions with Surfaces. J. Chem. Phys. 119, 3413-3420 (2003)

102. Laskin, J., Futrell, J.H.: On the Efficiency of Energy Transfer in Collisional Activation of Small Peptides. J. Chem. Phys. 116, 4302-4310 (2002)

103. Meroueh, S.O., Wang, Y., Hase, W.L.: Direct Dynamics Simulations of Collision- and Surface-Induced Dissociation of $\mathrm{N}$-Protonated Glycine. Shattering Fragmentation. J. Phys. Chem. A 106, 9983-9992(2002)

104. Wang, Y., Hase, W.L., Song, K.: Direct Dynamics Study of N-Protonated Diglycine SurfaceInduced Dissociation. Influence of Collision Energy. J. Am. Soc. Mass Spectrom. 14, 1402-1412 (2003)

105. Wang, J., Meroueh, S.O., Wang, Y., Hase, W.L.: Efficiency of Energy Transfer in Protonated Diglycine and Dialanine SID. Effects of Collision Angle, Peptide Ion Size, and Intramolecular Potential. Int. J. Mass Spectrom. 230, 57-64 (2003) 
106. Rahaman, A., Zhou, J.B., Hase, W.L.: Effects of Projectile Orientation and Surface Impact Site on the Efficiency of Projectile Excitation in Surface-Induced Dissociation. Protonated Diglycine Collisions with Diamond \{111\}. Int. J. Mass Spectrom. 249-250, 321-329 (2006)

107. Park, K., Song, K., Hase, W.L.: An Ab Initio Direct Dynamics Simulation of Protonated Glycine Surface-Induced Dissociation. Int. J. Mass Spectrom. 265, 326-336 (2007)

108. Yang, L., Mazyar, O.A., Lourderaj, U., Wang, J., Rodgers, M.T., Martínez-Núñez, E., Addepalli, S.V., Hase, W.L.: Chemical Dynamics Simulations of Energy Transfer in Collisions of Protonated Peptide Ions with a Perfluorinated Alkylthiol Self-Assembled Monolayer Surface. J. Phys. Chem. C 112, 9377-9386 (2008)

109. Park, K, Deb, B., Song, K., Hase, W.L.: Importance of Shattering Fragmentation in the Surface-Induced Dissociation of Protonated Octaglycine. J. Am. Soc. Mass Spectrom. 20, 939948 (2009)

110. Barnes, G.L., Hase, W.L.: Energy Transfer, Unfolding, and Fragmentation Dynamics in Collisions of N-Protonated Octaglycine with an H-SAM surface. J. Am. Chem. Soc. 131, 17185$17193(2009)$

111. Pratihar, S., Kohale, S.C., Bhakta, D.G., Laskin, J., Hase, W.L.: Dynamics of Energy Transfer and Soft-Landing in Collisions of Protonated Dialanine with Perfluorinated Self-Assembled Monolayer Surfaces. Phys. Chem. Chem. Phys. 16, 23769-23778 (2014)

112. Yang, Z., Hadjar, O., Laskin, J.: Effect of Surface Morphology on the Energy Transfer in IonSurface Collisions. Int. J. Mass Spectrom. 265, 124-129 (2007)

113. Dismmukes, J. P., Ravi, K.V. Proceedings of the Third International Symposium on Diamond Materials. The Electrochemical Society: Pennington, NJ (1993)

114. Meroueh, O., Hase, W.L.: Energy Transfer Pathways in the Collisional Activation of Peptides. Int. J. Mass Spectrom. 201, 233-244 (2000)

115. Rahaman, A., Collins, O., Scott, C., Wang, J., Hase, W. L.: Role of Projectile and Surface Temperatures in the Energy Transfer Dynamics of Protonated Peptide Ion Collisions with the Diamond $\{111\}$ Surface. J. Phys. Chem. A 110, 8418-8422 (2006)

116. Levine, R.D., Bernstein, R.B.: Molecular Reaction Dynamics and Chemical Reactivity. Oxford: New York (1987)

117. Hase, W.L.: Unimolecular and Intramolecular Dynamics: Relationship to Potential Energy Surface Properties. J. Phys. Chem. 90, 365-374 (1986) 
118. Baer, T., Hase, W.L.: Unimolecular Reaction Dynamics. Theory and Experiments. Oxford: New York (1996)

119. Laskin, J., Bailey, T.H., Futrell, J.H.: Shattering of Peptide Ions on Self-Assembled Monolayer Surfaces. J. Am. Chem. Soc. 125,1625-1632 (2003)

120. Laskin, J., Futrell, J.H.: Surface-Induced Dissociation of Peptide Ions: Kinetics and Dynamics. J. Am. Soc. Mass Spectrom. 14, 1340-1347 (2003)

121. Klassen, J.S., Kebarle, P.: Collision-Induced Dissociation Threshold Energies of Protonated Glycine, Glycinamide, and Some Related Small Peptides and Amino Amides. J. Am. Chem. Soc. $119,6552-6563$ (1997)

122. Armentrout, P. B., Heaton, A. L., Ye, S. J.: Thermodynamics and Mechanisms for Decomposition of Protonated Glycine and its Protonated Dimer. J. Phys. Chem. A 115, 1114411155 (2011)

123. Vachet, R.W., Bishop, B.M., Erickson, B.W., Glish, G.L.: Novel Peptide Dissociation: GasPhase Intramolecular Rearrangement of Internal Amino Acid Residues. J. Am. Chem. Soc. 119, 5481-5488 (1997)

124. Farrugia, J.M., O’Hair, R.A.J.: Involvement of Salt Bridges in a Novel Gas Phase Rearrangement of Protonated Arginine-Containing Dipeptides which Precedes Fragmentation. Int. J. Mass Spectrom. 222, 229-242 (2003)

125. Yagüe, J., Paradela, A., Ramos, M., Ogueta, S., Marina, A., Barahona, F., López de Castro, J.A.; Vázquez, J.; Peptide Rearrangement during Quadrupole Ion Trap Fragmentation: Added Complexity to MS/MS Spectra. Anal. Chem. 75, 1524-1535 (2003)

126. Barnes, G.L., Young, K., Yang, L., Hase, W.L.: Fragmentation and Reactivity in Collisions of Protonated Diglycine with Chemically Modified Perfluorinated Alkylthiolate-SelfAssembled Monolayer Surfaces. J. Chem. Phys. 134, 094106 (2011)

127. Dongré, A.R.; Jones, J.L.; Somogyi, A.; Wysocki, V.H. Influence of Peptide Composition, Gas-Phase Basicity, and Chemical Modification on Fragmentation Efficiency: Evidence for Mobile Proton Model. J. Am. Chem. Soc. 118, 8365-8374 (1996)

128. Gregg, Z., Ijaz, W., Jannetti, S., Barnes, G.L.: The Role of Proton Transfer in Surface-Induced Dissociation. J. Phys. Chem. C 118, 22149-22155 (2014)

129. Ijaz, W., Gregg, Z., Barnes, G.L.: Complex Formation during SID and Its Effect on Proton Mobility. J. Phys. Chem. Lett. 4, 3935-3939 (2013) 
130. Pratihar, S., Kim, N., Kohale, S.C., Hase, W.L.: Mechanistic Details of Energy Transfer and Soft Landing in ala $2-\mathrm{H}^{+}$Collisions with a F-SAM Surface. Phys. Chem. Chem. Phys. 17, 24576$24586(2015)$

131. Kohale, S.C., Pratihar, S., Hase, W.L.: Chemical Dynamics Simulations of Thermal Desorption of Protonated Dialanine from a Perfluorinated Self-Assembled Monolayer Surface. J. Phys. Chem. Lett. 9, 1554-1560 (2018)

132. Frederickson, D., McDonough, M., Barnes, G.L.: A Computational Comparison of Soft Landing of Alpha-Helical vs Globular Peptides. J. Phys. Chem. B 122, 9549-9554 (2018)

133. Baxa, M.C., Haddadian, E.J., Jumper, J.M., Freed, K.F., Sosnick, T.R.: Loss of Conformational Entropy in Protein Folding Calculated Using Realistic Ensembles and Its Implications for NMR-Based Calculations. Proc. Natl. Acad. Sci. U. S. A. 111, 15396-15401 (2014)

134. Geragotelis, A., Barnes, G.L.: Surface Deposition Resulting from Collisions Between Diglycine and Chemically Modified Alkylthiolate Self-Assembled Monolayer Surfaces. J. Phys. Chem. C 117, 13087-13093 (2013)

135. Barnes, G.L., Podczerwinski, A.: Simulating the Effect of Charge State on Reactive Landing of a Cyclic Tetrapeptide on Chemically Modified Alkylthiolate Self-Assembled Monolayer Surfaces. J. Phys. Chem. C 121, 14628-14635 (2017)

136. Wang, P., Hadjar, O., Gassman, P.L., Laskin, J.: Reactive Landing of Peptide Ions on SelfAssembled Monolayer Surfaces: An Alternative Approach for Covalent Immobilization of Peptides on Surfaces. Phys. Chem. Chem. Phys. 10, 1512-1522 (2008)

137. Douglas, D.J.: Applications of Collision Dynamics in Quadrupol Mass Spectrometry. J. Am. Soc. Mass Spectrom. 9, 101-113 (1998).

138. Ortiz, D., Salpin, J.-Y., Song, K., Spezia, R.: Galactose 6-sulfate collision induced dissociation using QM+MM chemical dynamics simulations and ESI-MS/MS experiments. Int. J. Mass Spectrom. 358, 25-35 (2014).

139. Spezia, R., Cimas, A., Gaigeot, M.-P., Salpin, J.-Y., Song, K., Hase, W.L.: Collision Induced Dissociation of Doubly-charged Ions: Coulomb Explosion vs Neutral Loss in [Ca(urea) $]^{2+}$ Gas Phase Unimolecular Reactivity via Chemical Dynamics Simulations. Phys. Chem. Chem. Phys. 14, 11724-11736 (2012). 
140. Martin-Somer, A., Yanez, M., Gaigeot, M.-P., Spezia, R.: Unimolecular Fragmentation Induced By Low Energy Collision: Statistically Or Dynamically Driven? J. Phys. Chem. A 118, 10882-10893 (2014).

141. Rossich Molina, E., Ortiz, D., Salpin, J.Y., Spezia, R.: Elucidating collision induced dissociation products and reaction mechanisms of protonated uracil by coupling chemical dynamics simulations with tandem mass spectrometry experiments. J. Mass Spectrom. 50, 1340$1351(2015)$

142. Jeanvoine, Y., Gaigeot, M.-P., Hase, W.L., Song, K., Spezia, R.: Collision Induced Dissociation of Protonated Urea with a Diatomic Projectile: Effects on Energy Transfer and Reactivity via Chemical Dynamics Simulations. Int. J. Mass Spectrom. 308, 289-298 (2011) 143. de Sainte Claire, P., Peslherbe, G.H., Hase W.L.: Energy Transfer Dynamics in the CollisionInduced Dissociation of $\mathrm{Al}_{6}$ and $\mathrm{Al}_{13}$ Clusters. J. Phys. Chem. 99, 8147-8161 (1995)

144. Rodriguez-Fernandez, R., Vazquez, S.A., Martinez-Nunez, E. Collision-induced dissociation mechanisms of [Li(uracil)] $]^{+}$. Phys. Chem. Chem. Phys. 15, 7628-7637 (2013)

145. Knyazev, V.D., Stein, S.E.: Monte Carlo/RRKM/Classical Trajectories Modeling of Collisional Excitation and Dissociation of n-Butylbenzene Ion in Multipole Collision Cells of Tandem Mass Spectrometers. J. Phys. Chem. A 114, 6384-6393 (2010)

146. Homayoon, Z., Pratihar, S., Dratz, E., Snider, R., Spezia, R., Barnes, G., Macaluso, V., Martin-Somer, A., Hase, W.L. Model Simulations of the Thermal Dissociation of the TIK $\left(\mathrm{H}^{+}\right)_{2}$ tripeptide. Mechanisms and Kinetic Parameters. J. Phys. Chem. A 120, 8211-8227 (2016).

147. Rodgers, M.T., Armentrout, P.B.: Statistical Modeling of Competitive Threshold CollisionInduced Dissociation. J. Chem. Phys. 109, 1787-1800 (1998)

148. Armentrout, P.B.: Statistical Modeling of Sequential Collision-Induced Dissociation Thresholds. J. Chem. Phys. 126, 234302 (2007)

149. Amicangelo, J.C., Armentrout, P.B.: Relative and Absolute Bond Dissociation Energies of Sodium Cation Complexes Determined using Competitive Collision-Induced Dissociation Experiments. Int. J. Mass Spectrom. 212, 301-325 (2001)

150. Muntean, F., Armentrout, P.B.: Modeling Kinetic Shifts for Tight Transition States in Threshold Collision-Induced Dissociation. Case Study: Phenol Cation. J. Phys. Chem. B 106, 8117-8124 (2002) 
151. Muntean, F., Armentrout, P.B.: Modeling Kinetic Shifts and Competition in Threshold Collision-Induced Dissociation. Case Study: n-Butylbenzene Cation Dissociation. J. Phys. Chem. A $107,7413-7422(2003)$

152. Muntean, F., Heumann, L., Armentrout, P.B.: Modeling Kinetic Shifts in Threshold Collision-Induced Dissociation. Case Study: Dichlorobenzene Cation Dissociation. J. Chem. Phys. $116,5593-5602$ (2002)

153. Koizumi, H., Muntean, F., Armentrout, P.B.: Reaction of $\mathrm{Cu}^{+}$with Dimethoxyethane: Competition Between Association and Multiple Dissociation Channels. J. Chem. Phys. 120, 756766 (2004)

154. Koizumi, H., Armentrout, P.B.: The Kinetic Energy Dependence of Association Reactions. A New Thermokinetic Method for Large Systems. J. Chem. Phys. 119, 12819-12829 (2003)

155. Amicangelo, J.C., Armentrout, P.B.: Ligand Exchange Reactions of Sodium Cation Complexes Examined Using Guided Ion Beam Mass Spectrometry: Relative and Absolute Dissociation Free Energies and Entropies. J. Phys. Chem. A 108, 10698-10713 (2004)

156. Rossich Molina, E., Salpin, J.-Y., Spezia, R., Martínez-Núñez, E.: On the Gas Phase Fragmentation of Protonated Uracil: A Statistical Perspective. Phys. Chem. Chem. Phys. 18, 14980-14990 (2016)

157. Monge-Palacios, M., Nogueira, J.J., Martinez-Nunez, E.: Energy Transfer and Thermal Accommodation in Ozone Scattering from a Perfluorinated Self-Assembled Monolayer. J. Phys. Chem. C. 116, 25454-25464 (2012)

158. Nogueira, J.J., Hase, W.L., Martinez-Nunez, E.: Understanding Energy Transfer in GasSurface Collisions from Gas-Phase Models. J. Phys. Chem. C 118, 2609-2621 (2014)

159. Macaluso, V., Homayoon, Z., Spezia, R., Hase, W.L.: Threshold for Shattering Fragmentation in Collision-Induced Dissociation of Doubly Protonated Tripeptide TIK $\left(\mathrm{H}^{+}\right)_{2}$. Phys. Chem. Chem. Phys. 20, 19744-19749 (2018)

160. Fenn, P.T., Chen, Y.-J., Stimson, S., Ng, C.Y.: Dissociation of $\mathrm{CH}_{3} \mathrm{SH}^{+}$by Collisional Activation: Evidence of Nonstatistical Behavior. J. Phys. Chem. A 101, 6513-6522 (1997)

161. Martínez-Núñez, E., Vázquez, S.A., Marques, J.M.C.: Quasiclassical Trajectory Study of the Collision-Induced Dissociation of $\mathrm{CH}_{3} \mathrm{SH}^{+}+$Ar. J. Chem.Phys. 121, 2571 (2004) 
162. Chen, Y.-J., Fenn, P.T., Lau, K.-C., Ng, C.Y., Law, C.-K., Li, W.-K.: Study of the Dissociation of $\mathrm{CH}_{3} \mathrm{SCH}_{3}{ }^{+}$by Collisional Activation: Evidence of Nonstatistical Behavior. J. Phys. Chem. A 106, 9729-9736 (2002)

163. Martínez-Núñez, E., Vázquez, S.A., Aoiz, E.J., Castillo, J.F.: Quasiclassical Trajectory Study of the Collision-Induced Dissociation Dynamics of $\mathrm{Ar}+\mathrm{CH}_{3} \mathrm{SH}^{+}$Using an $\mathrm{Ab}$ Initio Interpolated Potential Energy Surface. J.Phys. Chem. A 110, 1225-1231 (2006)

164. Martínez-Núñez, E., Fernández-Ramos, A., Vázquez, S.A., Marques, J.M.C., Xue, M., Hase, W.L.: Quasiclassical dynamics simulation of the collision-induced dissociation of $\mathrm{Cr}(\mathrm{CO})^{+}{ }_{6}$ with Xe. J. Chem. Phys. 123, 154311 (2005)

165. Liu, J., Song, K., Hase, W.L., Anderson, S.L.: Direct Dynamics Study of Energy Transfer and Collision-Induced Dissociation: Effects of Impact Energy, Geometry, and Reactant Vibrational Mode in $\mathrm{H}_{2} \mathrm{CO}^{+}-\mathrm{Ne}$ Collisions. J. Chem. Phys. 119, 3040 (2003)

166. Spezia, R., Salpin, J.-Y., Gaigeot, M.-P., Hase, W.L., Song, K.: Protonated Urea CollisionInduced Dissociation. Comparison of Experiments and Chemical Dynamics Simulations. J. Phys. Chem. A 113, 13853-13862 (2009)

167. Spezia, R., Lee, S.B., Cho, A., Song, K.: Collision Induced Dissociation Mechanisms of Protonated Penta- and Octa-Glycine as Revealed by Chemical Dynamics Simulations. Int. J. Mass Spectrom. 392, 125-138 (2015)

168. Spezia, R., Martens, J., Oomens, J., Song, K.: Collision-Induced Dissociation Pathways of Protonated $\mathrm{Gly}_{2} \mathrm{NH}_{2}$ and $\mathrm{Gly}_{3} \mathrm{NH}_{2}$ in the Short Time-Scale Limit by Chemical Dynamics and Ion Spectroscopy. Int. J. Mass Spectrom. 388, 40-52 (2015)

169. Ortiz, D., Martin-Gago, P., Riera, A., Song, K., Salpin, J.-Y., Spezia, R.: Gas-Phase Collision Induced Dissociation Mechanisms of Peptides. Theoretical and Experimental Study of NFormylalanylamide Fragmentation. Int. J. Mass Spectrom. 335, 33-44 (2013)

170. Oomens, J., Young, S., Molesworth, S., van Stipdnok, M.: Spectroscopic Evidence for an Oxazolone Structure of the $b_{2}$ Fragment Ion from Protonated Tri-Alanine. J. Am. Soc. Mass Spectrom. 20, 334-339 (2009)

171. Chen, X., Tirado, M., Steill, J.D., Oomens, J., Polfer, N.C.: Cyclic Peptide as Reference System for b Ion Structural Analysis in the Gas Phase. J. Mass Spectrom. 46, 1011-1015 (2011) 172. Paizs, B., Lendvay, G., Vekey, K., Suhai, S.: Formation of $\mathrm{b}_{2}^{+}$Ions from Protonated Peptides: an Ab Initio Study. Rapid Commun. Mass Spectrom. 13, 525-533 (1999) 
173. Martin-Somer, A., Martens, J., Grzetic, J., Hase, W.L., Oomens, J., Spezia, R.: Unimolecular Fragmentation of Deprotonated Diproline $\left[\mathrm{Pro}_{2}-\mathrm{H}\right]^{-}$Studied by Chemical Dynamics Simulations and IRMPD Spectroscopy. J. Phys. Chem. A 122, 2612-2625 (2018)

174. Lee, G., Park, E., Chung, H., Jeanvoine, Y., Song, K., Spezia, R.: Gas Phase Fragmentation Mechanisms of Protonated Testosterone as Revealed by Chemical Dynamics Simulations. Int. J. Mass Spectrom. 407, 40-50 (2016)

175. Thevis, M., Beuck, S., Höppner, S., Thomas, A., Held, J., Schäfer, M., Oomens, J., Schänzer, W.: Structure Elucidation of the Diagnostic Product Ion at m/z 97 Derived from Androst-4-en-3One- Based Steroids by ESI-CID and IRMPD Spectroscopy. J. Am. Soc. Mass Spectrom. 23, 537$546(2012)$

176. Williams, T., Kind, A., Houghton, E., Hill, D.: Electrospray collision-induced dissociation of testosterone and testosterone hydroxy analogs, J. Mass Spectrom. 34, 206-216 (1999)

177. Pozo, O.J., Van Eenoo, P., Deventer, K., Grimalt, S., Sancho, J.V., Hernández, F., Delbeke, F.T.: Collision-induced dissociation of 3-keto anabolic steroids and related compounds after electrospray ionization. Considerations for structural eleucidation, Rapid Commun. Mass Spectrom. 22, 4009-4024 (2008)

178. Martínez-Núñez, E.: An Automated Transition State Search Using Classical Trajectories Initialized at Multiple Minima. Phys. Chem. Chem. Phys., 17, 14912-14912 (2015)

179. Martínez-Núñez, E.: An Automated Method to Find Transition States Using Chemical Dynamics Simulations. J. Comput. Chem., 36, 222-234 (2015)

180. Rodríguez, A., Rodríguez-Fernańdez, R., Vaźquez, S.A., Barnes, G.L., Stewart, J.J.P., Martínez-Nunez, E. Tsscds2018: A Code for Automated Discovery of Chemical Reaction Mechanisms and Solving the Kinetics. J. Comput. Chem. 39, 1922-1930 (2018)

181. Macaluso, V., Scuderi, D., Crestoni, M.E., Fornarini, S., Corinti, D., Dalloz, E., MartinezNunez, E., Hase, W.L., Spezia, R.: L-Cysteine Modified by S-Sulfation: Consequence on Fragmentation Processes Elucidated by Tandem Mass Spectrometry and Chemical Dynamics Simulations. J. Phys. Chem. A 123, 3685-3696 (2019)

182. Nelson, C.C., McCloskey, J.A.: Collision-induced dissociation of uracil and its derivatives. J. Am. Soc. Mass Spectrom. 5, 339-349 (1994) 
183. Beach, D.G., Gabryelski, W.: Revisiting the reactivity of uracil during collision induced dissociation: tautomerism and charge-directed processes. J. Am. Soc. Mass Spectrom. 23, 858868 (2012)

184. Sadr-Arani, L., Mignon, P., Chermette, H., Douki, T.: Theoretical and experimental study of the fragmentation of protonated uracil. Chem. Phys. Lett. 605-606, 108-114 (2014)

185. Homayoon, Z., Macaluso, V., Martin-Somer, A., Pratihar, S., Hase, W.L., Spezia, R.: Chemical Dynamics Simulations of Peptide Ion CID. Comparison between $\mathrm{TIK}\left(\mathrm{H}^{+}\right)_{2}$ and TLK $\left(\mathrm{H}^{+}\right)_{2}$ Fragmentation Dynamics and with Thermal Simulations. Phys. Chem. Chem. Phys. 20, 3614-3629 (2018)

186. Spezia, R., Martin-Somer, A., Macaluso, V., Homayoon, Z., Pratihar, S., Hase, W.L.: Unimolecular Dissociation of Peptides: Statistical vs Non-Statistical Fragmentation Mechanisms and Time Scales. Faraday Discuss. 195, 599-618 (2016)

187. Tuckerman, M.A.: Statistical Mechanics: Theory and Molecular Simulation. Oxford University Press, New York (2010)

188. Yang, L.; Sun, R.; Hase, W. L.: Use of Direct Dynamics Simulations to Determine Unimolecular Reaction Paths and Arrhenius Parameters for Large Molecules. J. Chem. Theory Comput. 7, 3478-3483 (2011)

189. Elstner, M., Porezag, D., Jungnickel, G., Elsner, J., Haugk, M., Frauenheim, T., Suhai, S., Seifert, G.: Self-Consistent-Charge Density-Functional Tight-Binding Method for Simulations of Complex Materials Properties. Phys. Rev. B 58, 7260 (1998)

190. Bowman, J.M., Gazdy, B., Sun, Q.: A Method to Constrain Vibrational Energy in QuasiClassical Trajectory Calculations. J. Chem. Phys. 91, 2859 (1989)

191. Paul, A., Hase, W.L.: Zero-Point Energy Constraint for Unimolecular Dissociation Reactions. Giving Trajectories Multiple Chances To Dissociate Correctly. J. Phys. Chem. A 120, 372-378 (2016)

192. Miller, W.H., Hase, W.L., Darling, C.L.: A Simple Model for Correcting the Zero Point Energy Problem in Classical Trajectory Simulations of Polyatomic Molecules. J. Chem. Phys. 91, 2863 (1989)

193. Rossich Molina, E., Eizaguirre, A., Haldys, V., Urban, D., Doisneau, G., Bourdreux, Y., Beau, J.-M., Salpin, J.-Y., Spezia, R.: Characterization of Protonated Model Disaccharides from 
Tandem Mass Spectrometry and Chemical Dynamics Simulations. ChemPhysChem 18, 28122823 (2017)

194. Knyazev, V.D., Stein, S.E.: Classical Trajectories and RRKM Modeling of Collisional Excitation and Dissociation of Benzylammonium and tert-Butyl Benzylammonium Ions in a Quadrupole-Hexapole-Quadrupole Tandem Mass Spectrometer. J. Am. Soc. Mass Spectrom. 21, 425-439 (2010)

195. Czako, G., Kaledin, A.L., Bowman, J.M.: A Practical Method to Avoid Zero-Point Leak in Molecular Dynamics Calculations: Application to the Water Dimer. J. Chem. Phys. 132, 164103 (2010)

196. Lim, K. F., McCormack, D.A.: The Conservation of Quantum Zero-point Energies in Classical Trajectory Simulations. J. Chem. Phys. 102, 1705 (1995)

197. McCormack, D.A., Lim, K.F.: The Zero-Point Energy Problem in Classical Trajectory Simulations at Dissociation Threshold. J. Chem. Phys. 106, 572 (1997)

198. Meyer, H.-D., Manthe, U., Cederbaum, L.S.: The Multi-Configurational Time-Dependent Hartree Approach. Chem. Phys. Lett. 165, 73-78 (1990)

199. Cao, J., Voth, G.A.: The Formulation of Quantum Statistical Mechanics Based on the Feynman Path Centroid Density. I. Equilibrium Properties. J. Chem. Phys. 100, 5093 (1994).

200. Craig, I.R., Manolopoulos, D.E.: Quantum Statistics and Classical Mechanics: Real Time Correlation Functions from Ring Polymer Molecular Dynamics. J. Chem. Phys. 121, 3368 (2004) 201. Dammak, H., Chalopin, Y., Laroche, M., Hayoun, M., Greffet, J.-J.: Quantum Thermal Bath for Molecular Dynamics Simulation. Phys. Rev. Lett. 103, 190601 (2009)

202. Spezia, R., Dammak, H. On the Use of Quantum Thermal Bath in Unimolecular Fragmentation Simulations. J. Phys. Chem. A 123, 8542-8551 (2019).

203. Herman, M.F., Kluk E.: A Semiclassical Justification for the Use of Non-spreading Wavepackets in Dynamics Calculations. Chem. Phys. 91, 27-34 (1984)

204. Heller, E.J.: Frozen Gaussians: A Very Simple Semiclassical Approximation. J. Chem. Phys. $75,2923(1981)$

205. Huber, D., Heller, E.J.: Generalized Gaussian Wave Packet Dynamics. J. Chem. Phys. 87, 5302 (1987)

206. Nakata, H., Bai, S.: Development of a new parameter optimization scheme for a reactive force field based on a machine learning approach. J. Comput. Chem. 40, 2000-2012 (2019) 
207. Chang, K.Y.S., Fias, S., Ramakrishnan, R., von Lilienfeld, A.O.: Fast and accurate predictions of covalent bonds in chemical space. J. Chem. Phys. 144, 174100 (2016)

208. von Lilienfeld, A.O.: Quantum Machine Learning in Chemical Compound Space. Angew. Chem. Int. Ed. 57, 4164-4169 (2018).]

209. Schwarz, H.: Metal-mediated Activation of Carbon Dioxide in the Gas Phase: Mechanistic Insight Derived from a Combined Experimental/Computational Approach. Coord. Chem. Rev. 334, 112-123 (2017)

210. Schwarz, H.: Ménage-à-trois: Single-Atom Catalysis, Mass Spectrometry, and Computational Chemistry. Catal. Sci. Technol. 7, 4302-4314 (2017) 
Table 1. Energy Transfer Dynamics for Peptide-H ${ }^{+}$Collisions with Organic Surfaces ${ }^{\text {a }}$

\begin{tabular}{|c|c|c|c|c|c|c|c|}
\hline Peptide- $^{+}$ & Surface & $\begin{array}{c}E_{i} \\
(\mathrm{eV}) \\
\end{array}$ & $\begin{array}{l}\theta_{i} \\
\left({ }^{\circ}\right) \\
\end{array}$ & $\begin{array}{l}\Delta E_{\text {int }} \\
(\%)\end{array}$ & $\begin{array}{c}\Delta E_{\text {surf }} \\
(\%) \\
\end{array}$ & $\begin{array}{l}\Delta E_{f} \\
(\%)\end{array}$ & ref. \\
\hline $\mathrm{gly}_{3}-\mathrm{H}^{+}$folded & H-SAM & 30 & 45 & 7 & 63 & 30 & 95 \\
\hline $\mathrm{gly}_{3}-$ & H-SAM & 30 & 45 & 8 & 54 & 38 & 95 \\
\hline \multirow{8}{*}{ gly $_{8}-\mathrm{H}^{+} \mathrm{H}-\mathrm{SAM}$} & & 5 & 0,45 & 12,10 & 57,38 & 30,52 & $111^{\mathrm{b}}$ \\
\hline & & 10 & 0,45 & 11,11 & 66,48 & 23,40 & \\
\hline & & 30 & 0,45 & 11,13 & 74,62 & 16,26 & \\
\hline & & 50 & 0,45 & 11,13 & 76,67 & 14,20 & \\
\hline & & 70 & 0,45 & 13,11 & 76,71 & 13,16 & \\
\hline & & 90 & 0,45 & 12,13 & 77,72 & 11,14 & \\
\hline & & 100 & 0,45 & 12,13 & 76,73 & 12,13 & \\
\hline & & 110 & 0,45 & 13,13 & 77,74 & 10,12 & \\
\hline \multirow[t]{5}{*}{ ala $_{2}-\mathrm{H}^{+}$} & F-SAM & 5 & 0,45 & 19,22 & 73,62 & 8,16 & 112 \\
\hline & & 13.5 & 0 & 18 & 71 & 11 & \\
\hline & & 22.5 & 0,45 & 20,23 & 76,61 & 4,16 & \\
\hline & & 30 & 0 & 19 & 78 & 3 & \\
\hline & & 70 & 0 & 17 & 81 & 2 & \\
\hline gly- $\mathrm{H}^{+}$ & diamond & 70 & 0,45 & 17,11 & 47,39 & 36,50 & $108^{c}$ \\
\hline \multirow[t]{6}{*}{$\mathrm{gly}_{2}-\mathrm{H}^{+}$} & diamond & 5 & 45 & 16 & 0 & 84 & 106 \\
\hline & & 10 & 45 & 17 & 4 & 79 & 106 \\
\hline & & 30 & 0,45 & 24,16 & 27,12 & 49,72 & (d) \\
\hline & & 50 & 0 & 21 & 37 & 42 & 105 \\
\hline & & 70 & 0,45 & 20,15 & 40,25 & 40,60 & (d) \\
\hline & & $100^{\mathrm{e}}$ & 0,45 & 17,13 & 48,34 & 35,53 & (d) \\
\hline \multirow[t]{5}{*}{$\operatorname{ala}_{2}-\mathrm{H}^{+}$} & diamond & 5 & 45 & 19 & 1 & 80 & 105 \\
\hline & & 10 & 45 & 19 & 5 & 76 & \\
\hline & & 30 & 45 & 18 & 12 & 70 & \\
\hline & & 70 & 45 & 21 & 21 & 58 & \\
\hline & & $100^{\mathrm{c}}$ & 45 & 15 & 31 & 54 & \\
\hline \multirow[t]{4}{*}{ gly $_{3}-\mathrm{H}^{+}$folded } & diamond & 10 & 45 & 8 & 2 & 89 & 95 \\
\hline & & 30 & 45 & 18 & 9 & 73 & \\
\hline & & 70 & 45 & 17 & 21 & 60 & \\
\hline & & 110 & 45 & 14 & 29 & 57 & \\
\hline \multirow{2}{*}{$\begin{array}{c}\text { gly }_{5}-\mathrm{H}^{+} \text {folded } \\
\text { gly }_{8}-\mathrm{H}^{+}\end{array}$} & diamond & 30 & 45 & 23 & 5 & 72 & 95 \\
\hline & diamond & 100 & 0,45 & 45,26 & 26,12 & 29,62 & $110^{\mathrm{f}}$ \\
\hline
\end{tabular}

a. The simulations are performed with the AMBER molecular mechanics (MM) force field for the peptide ion's intramolecular potential, unless otherwise noted.

b. The simulations were performed with RM1 for the peptide ion's intramolecular potential.

c. The simulations were performed with MP2 for the peptide ion's intramolecular potential.

d. $0^{\circ}$ results are AM1 from ref. 136 and $45^{\circ}$ results are AMBER from ref. 105.

e. The $45^{\circ}$ result is for $E_{i}=110 \mathrm{eV}$.

f. The simulations were performed with AM1 for the peptide ion's intramolecular potential. 
Table 2. Peptide-H ${ }^{+}$Intramolecular Potential and Energy Transfer Efficiencies

\begin{tabular}{|c|c|c|c|c|c|}
\hline Potential & $\begin{array}{l}E_{i} \\
(\mathrm{eV})\end{array}$ & $\begin{array}{l}\Delta E_{\text {int }} \\
(\%)\end{array}$ & $\begin{array}{l}\Delta E_{\text {surf }} \\
(\%)\end{array}$ & $\begin{array}{l}E_{f} \\
(\%)\end{array}$ & Ref. \\
\hline \multicolumn{6}{|c|}{ gly $-\mathrm{H}^{+}+$diamond, $\theta_{i}=45^{\circ}$} \\
\hline AMBER & 70 & 11 & 37 & 52 & 104 \\
\hline AM1 & 70 & 12 & 38 & 50 & 104 \\
\hline MP2 & 70 & 11 & 39 & 50 & 108 \\
\hline
\end{tabular}

\begin{tabular}{llcccc}
\multicolumn{5}{c}{$\mathrm{gly}_{2}-\mathrm{H}^{+}+$diamond, $\theta_{i}=0^{\circ}$} \\
AMBER & 35 & 27 & 29 & 44 & 107 \\
AM1 & 30 & 24 & 27 & 49 & 105 \\
AMBER & 70 & 22 & 41 & 37 & 107 \\
AM1 & 70 & 20 & 40 & 40 & 105
\end{tabular}

\begin{tabular}{lccccc}
\multicolumn{5}{c}{ gly $_{2}-\mathrm{H}^{+}+$diamond, $\theta_{i}=45^{\circ}$} \\
AMBER & 70 & 15 & 25 & 60 & 106 \\
AM1 & 70 & 12 & 27 & 61 & 105 \\
\hline
\end{tabular}


Table 3. Percentage of Shattering SID in QM+MM Direct Dynamics Simulations with a Diamond $\{111\}$ Surface

\begin{tabular}{ccccccc}
\hline Peptide- $^{+}$ & $\mathrm{QM}^{\mathrm{a}}$ & $\begin{array}{c}E_{i} \\
(\mathrm{eV})\end{array}$ & $\begin{array}{c}\theta_{i} \\
\left({ }^{\circ}\right)\end{array}$ & $\begin{array}{c}\text { Shattering }^{\mathrm{b}} \\
(\%)\end{array}$ & Channels $^{\mathrm{c}}$ & Ref. \\
\hline${\text { gly- } \mathrm{H}^{+}}^{+}$ & AM1 & 70 & 45 & 23 & 18 & 103 \\
gly- $^{+}$ & MP2 & 70 & 0 & 57 & 96 & 107 \\
& & & 45 & 22 & 14 & \\
gly $_{2}-\mathrm{H}^{+}$ & AM1 & 30 & 0 & 8 & 6 & 104 \\
& & 50 & 0 & 13 & 23 & \\
& & 70 & 0 & 44 & 44 & \\
gly $_{8}-\mathrm{H}^{+}$ & & 100 & 0 & 71 & 59 & \\
& AM1 & 100 & 0 & 78 & 304 & 109 \\
& & & 45 & 22 & $-{ }^{d}$ & \\
\hline
\end{tabular}

a. Quantum mechanical method for the direct dynamics.

b. Percentage of the fragmentations which are shattering.

c. Number of different fragmentation channels.

d. Not determined. 
Table 4. Summary of results obtained in collisional dynamics of different systems, as a function of collision energy ( $\left.E_{\text {col }}\right)$, percentage of transferred energy ( $\left.E_{\text {transf }}\right)$, of rotational activation $\left(E_{\text {rot }}\right)$ and shattering mechanisms.

\begin{tabular}{|c|c|c|c|c|c|}
\hline Collision System & $\mathrm{E}_{\mathrm{col}}^{\mathrm{a}}$ & $\begin{array}{l}E_{\text {transf }}^{b} \\
(\%)\end{array}$ & $\begin{array}{l}\mathrm{E}_{\mathrm{rot}}^{\mathrm{c}} \\
(\%)\end{array}$ & $\begin{array}{l}\text { Shattering }{ }^{\mathrm{d}} \\
(\%)\end{array}$ & Reference \\
\hline \multirow[t]{3}{*}{$\mathrm{UreaH}^{+}+\mathrm{Ar}$} & 4.40 & 33 & 22 & 12 & 166 \\
\hline & 5.66 & 32 & 20 & 33 & 166 \\
\hline & 6.29 & 35 & 21 & 41 & 166 \\
\hline $\mathrm{UreaH}^{+}+\mathrm{N}_{2}$ & 6.29 & 19 & 13 & 14 & 142 \\
\hline \multirow[t]{2}{*}{$\mathrm{CaUrea}^{2+}+\mathrm{Ar}$} & 9.11 & 29 & 13 & - & 139 \\
\hline & 13.00 & 20 & 8 & - & 139 \\
\hline \multirow{3}{*}{$\mathrm{CaForm}^{2+}+\mathrm{Ar}$} & 7.80 & 14 & 11 & - & 140 \\
\hline & 9.97 & 10 & 8 & - & 140 \\
\hline & 12.14 & 9 & 6 & - & 140 \\
\hline \multirow[t]{3}{*}{ SrForm $^{2+}+\mathrm{Ar}$} & 7.80 & 9 & 6 & - & 140 \\
\hline & 9.97 & 8 & 5 & - & 140 \\
\hline & 12.14 & 7 & 4 & - & 140 \\
\hline $\mathrm{H}^{+}-\mathrm{Gly}_{2} \mathrm{NH}_{2}+\mathrm{Ar}$ & 15.18 & 8 & 3 & - & 168 \\
\hline $\mathrm{H}^{+}-\mathrm{Gly}_{3} \mathrm{NH}_{2}+\mathrm{Ar}$ & 15.18 & 12 & 0.7 & - & 168 \\
\hline $\mathrm{H}^{+}-\mathrm{Gly}_{5} \mathrm{NH}_{2}+\mathrm{Ar}$ & 15.18 & 51 & 3 & 51 & 167 \\
\hline $\mathrm{H}^{+}-\mathrm{Gly}_{5} \mathrm{OH}+\mathrm{Ar}$ & 15.18 & 14 & 0.6 & 50 & 167 \\
\hline $\mathrm{H}^{+}-\mathrm{Gly}_{8} \mathrm{NH}_{2}+\mathrm{Ar}$ & 15.18 & 22 & 0.7 & 55 & 167 \\
\hline $\mathrm{H}^{+}-\mathrm{Gly}_{8} \mathrm{OH}+\mathrm{Ar}$ & 15.18 & 48 & 1 & 81 & 167 \\
\hline $\mathrm{PrO}_{2}^{-}+\mathrm{Ar}$ & 13.01 & 20 & - & - & 173 \\
\hline \multirow{3}{*}[\mathrm{TIK}+2\mathrm{H}]{$^{2+}+\mathrm{N}_{2}$} & 10.8 & 23 & & 50.8 & 185 \\
\hline & 12.9 & 18 & & 57.8 & 185 \\
\hline & 30 & 3.5 & & 91.6 & 185 \\
\hline$[\mathrm{TLK}+2 \mathrm{H}]^{2+}+\mathrm{N}_{2}$ & 12.9 & 11 & 1 & 42 & 185 \\
\hline Testosterone $\mathrm{H}^{+}+\mathrm{Al}_{1}$ & 30 & & - & $22^{\mathrm{e}}$ & 174 \\
\hline
\end{tabular}

a. Collision energy in $\mathrm{eV}$ in the center-of-mass frame.

b. Percentage of total energy transfer (average values calculated over non-reactive trajectories).

c. Percentage of the energy transfer to the polyatomic ion that is rotational energy (average values calculated over non-reactive trajectories).

d. Percentage of the ion fragmentation (over the reactive trajectories) that is shattering.

e. Shattering \% for the most important fragments for which absolute number of trajectories are reported and global \% can be obtained. Details for shattering vs fragment are reported in the original publication, Ref. 174. 


\section{Figure Captions}

Figure 1. Comparison between intermolecular potential energy curves for $\mathrm{CF}_{4}$ interacting with the $-\mathrm{NH}_{2}$ group of $\mathrm{HCONH}_{2}$ for different orientations; MP2-aug-ccpVTZ (solid circles) and fitted analytic potential (solid lines). (Reprinted with permissions from ref. 92. Copyright 2014 American Chemical Society).

Figure 2. Distributions of energy transfer to $\Delta E_{\text {int }}, \Delta E_{\text {surf }}$, and $E_{f}$ for $\mathrm{gly}_{2}-\mathrm{H}^{+}+$diamond $\{111\}$ collisions at $E_{i}=70 \mathrm{eV}$ and $\theta_{i}=45^{\circ}$. Simulations for the AMBER (----) and AM1 (-) models for the $\mathrm{gly}_{2}-\mathrm{H}^{+}$intramolecular potential are compared. (Reprinted with the permissions from ref. 105. Copyright 2003 Elsevier B.V.).

Figure 3. Ensemble averages of the internal energy of folded gly $\mathrm{y}_{3}-\mathrm{H}^{+}$versus time for $E_{i}=10$ (upper left), 30 (upper right), 70 (lower left), and $110 \mathrm{eV}$ (lower right) collisions with diamond $\{111\}$.

Figure 4. $\mathrm{N}_{2}-\mathrm{CH}_{3} \mathrm{OH}$ intermolecular potential energy curves (different orientations are shown) as obtained from RM1, QCSID(T) and analytical potential (MM) of Eq.1.

Figure 5. Energy transfer distribution as obtained in collisional dynamics of $[\mathrm{TIK}+2 \mathrm{H}]^{2+}$ with $\mathrm{N}_{2}$ using a collision energy of $9.76 \mathrm{eV}$ in the center-of-mass reference frame. Reactive and nonreactive trajectories are shown in red and black, respectively.

Figure 6. Example of reaction of protonated aminated-di-glycine forming first a linear $b^{+}$ion $(\mathrm{m} / z$ 115) via a shattering mechanism followed by a rearrangement consisting in cyclization leading to oxazolone ion.

Figure 7. Mass spectra of protonated testosterone as obtained by CID simulations (left) and experiments (right). Figures are adapted from Ref. 174 and Ref. 175 for theory and simulations respectively. Reproduced by permission of the Elsevier B.V. (left panel) and Springer Nature (right panel). 
Figure 8. Schematic picture of single collision (panel A) vs multiple collision (panel B) activation of a model Morse oscillator leading to dissociation. 

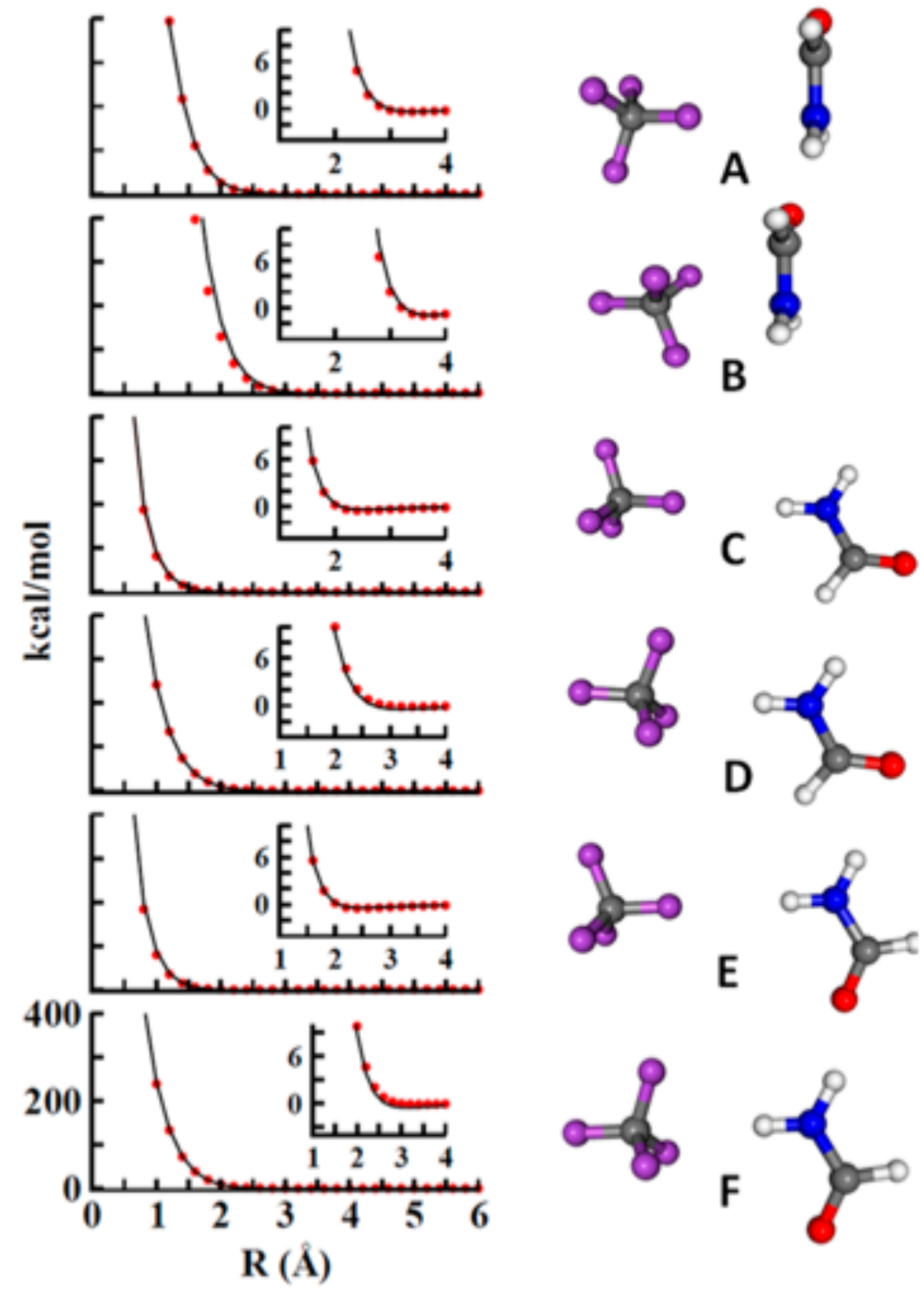

Figure 1. 

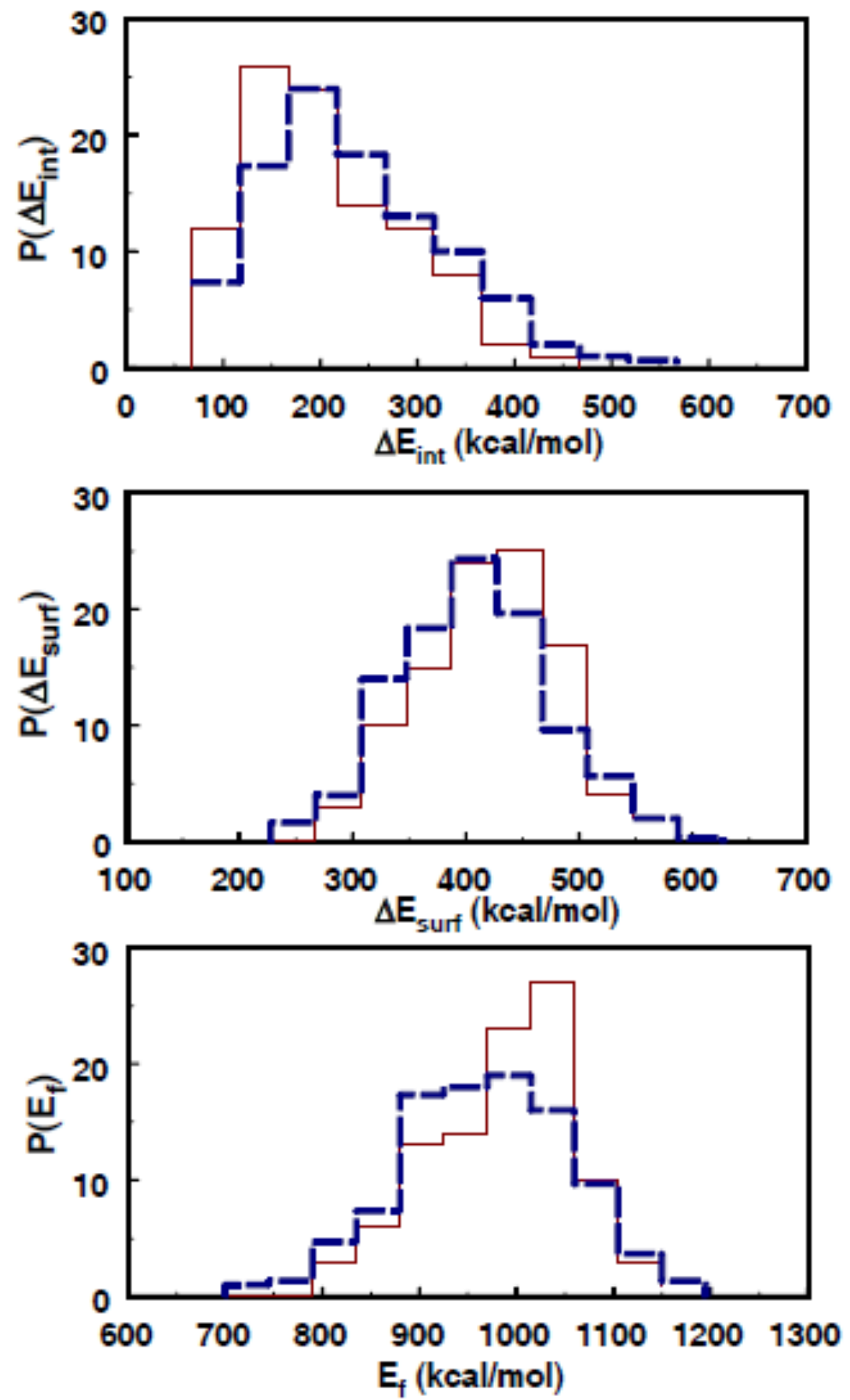

Figure 2. 

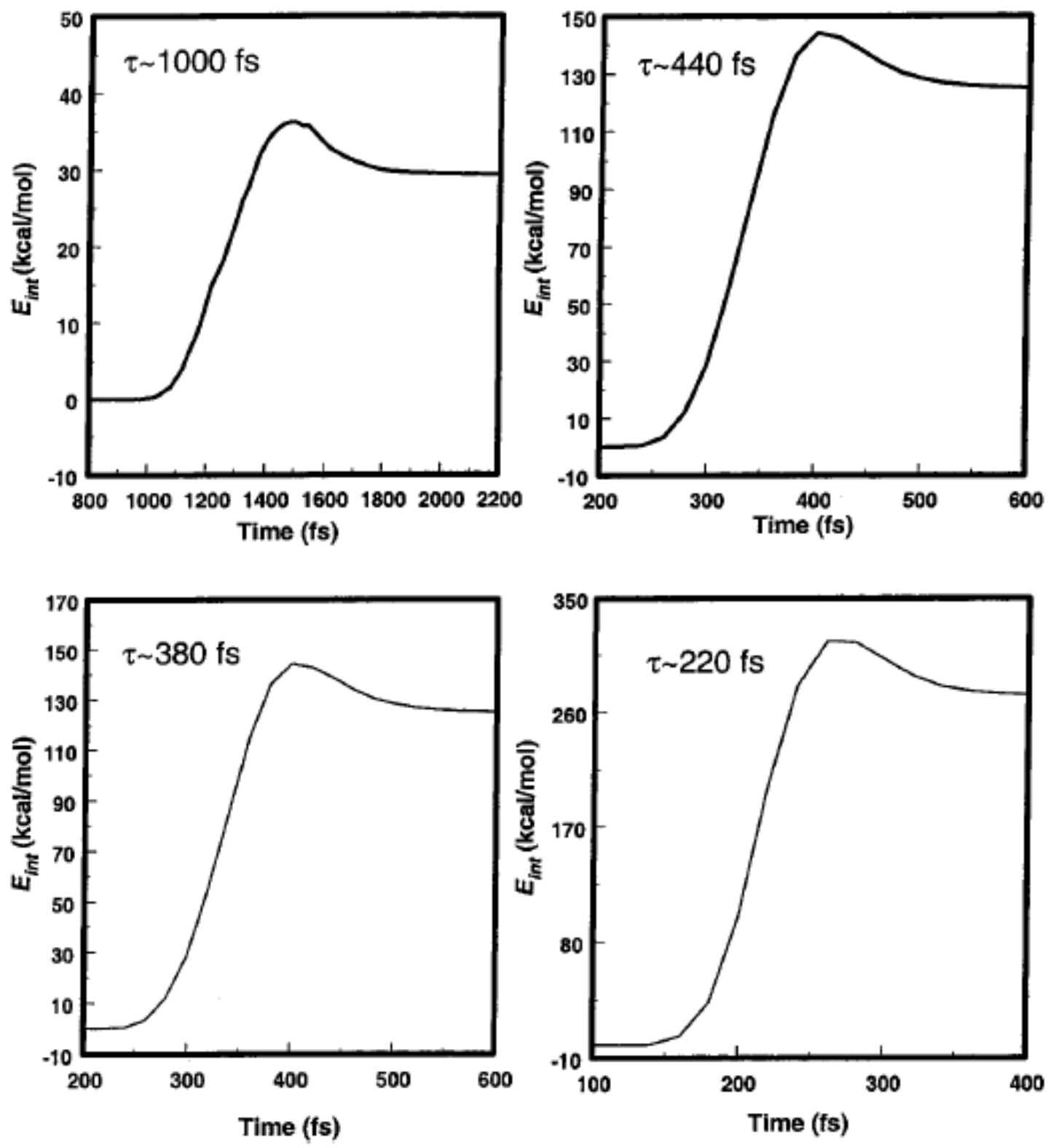

Figure 3. 

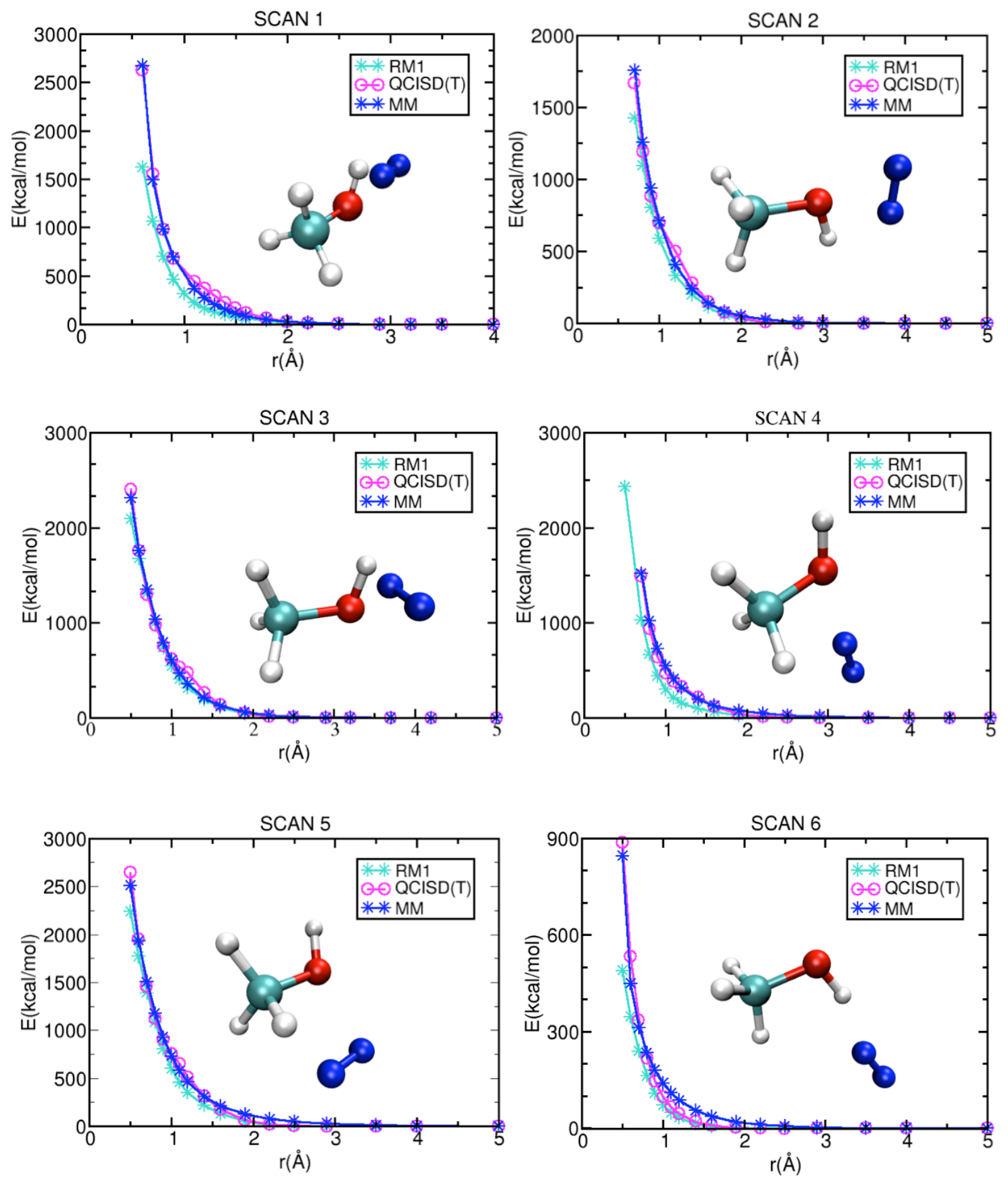

Figure 4. 


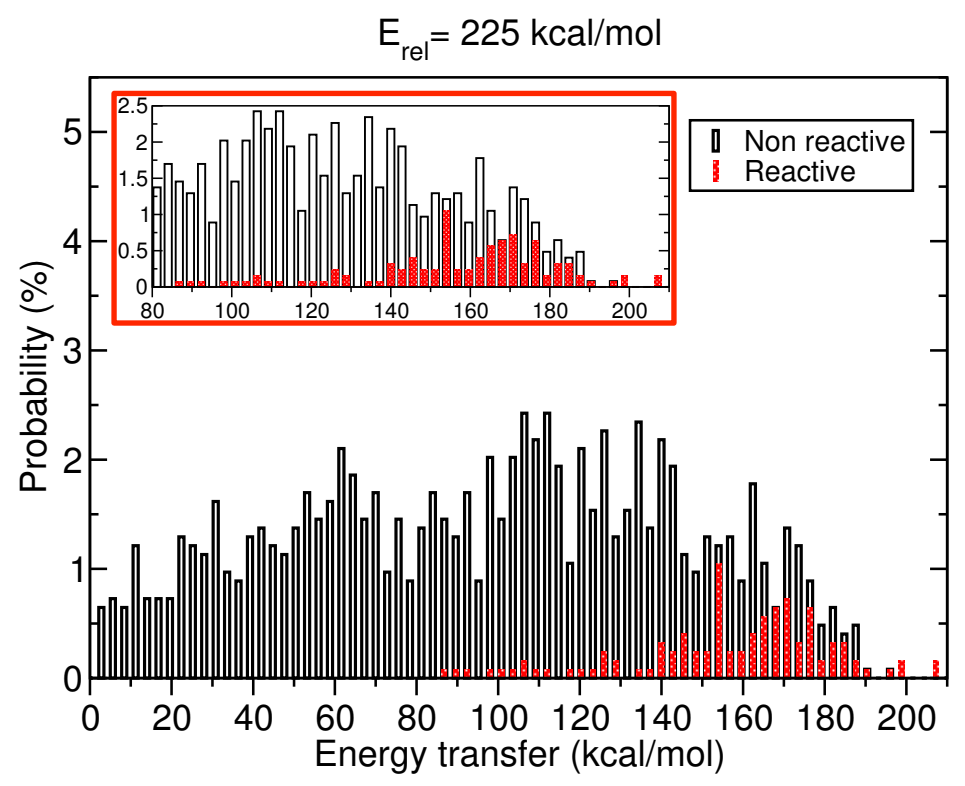

Figure 5. 


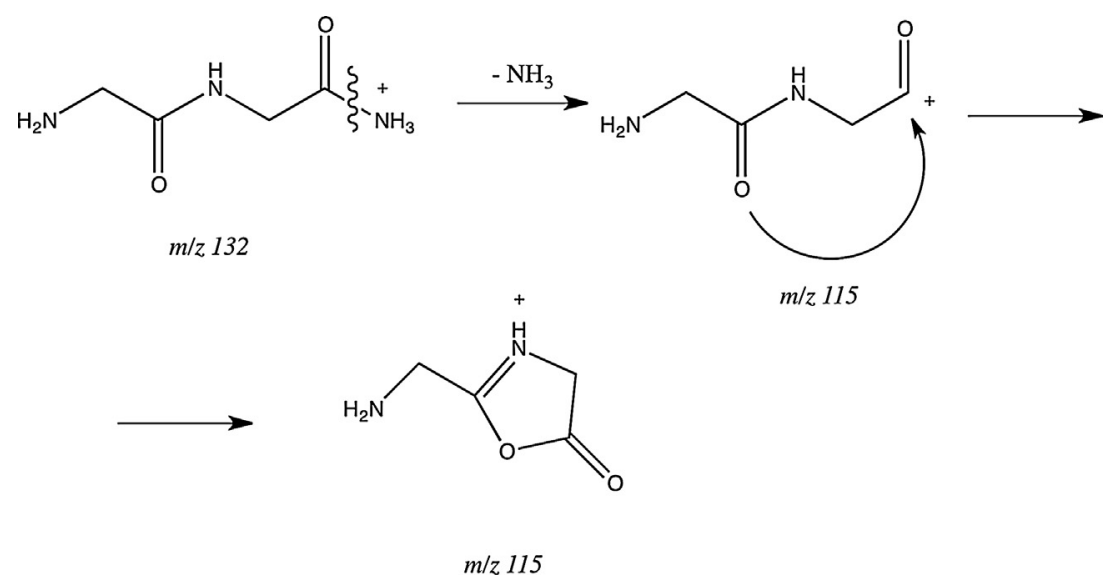

Figure 6. 

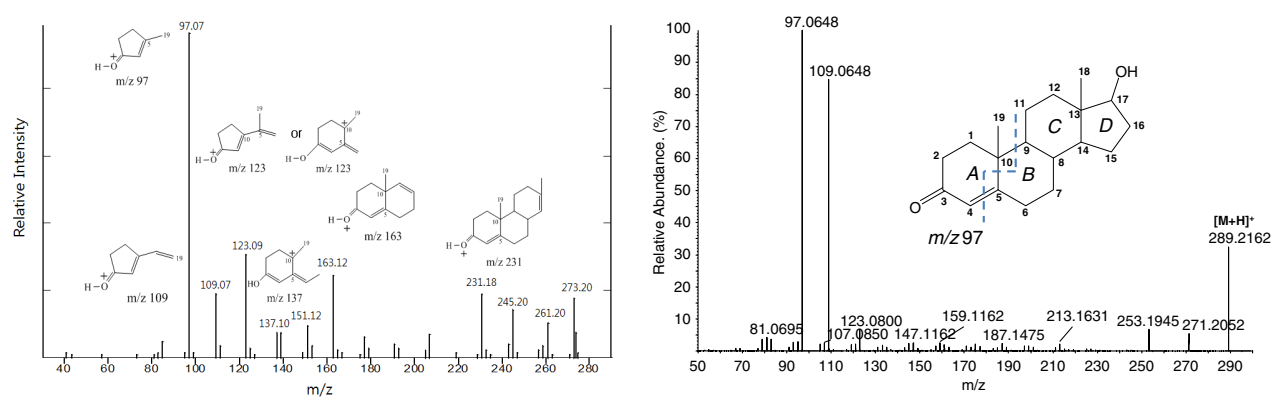

Figure 7. 


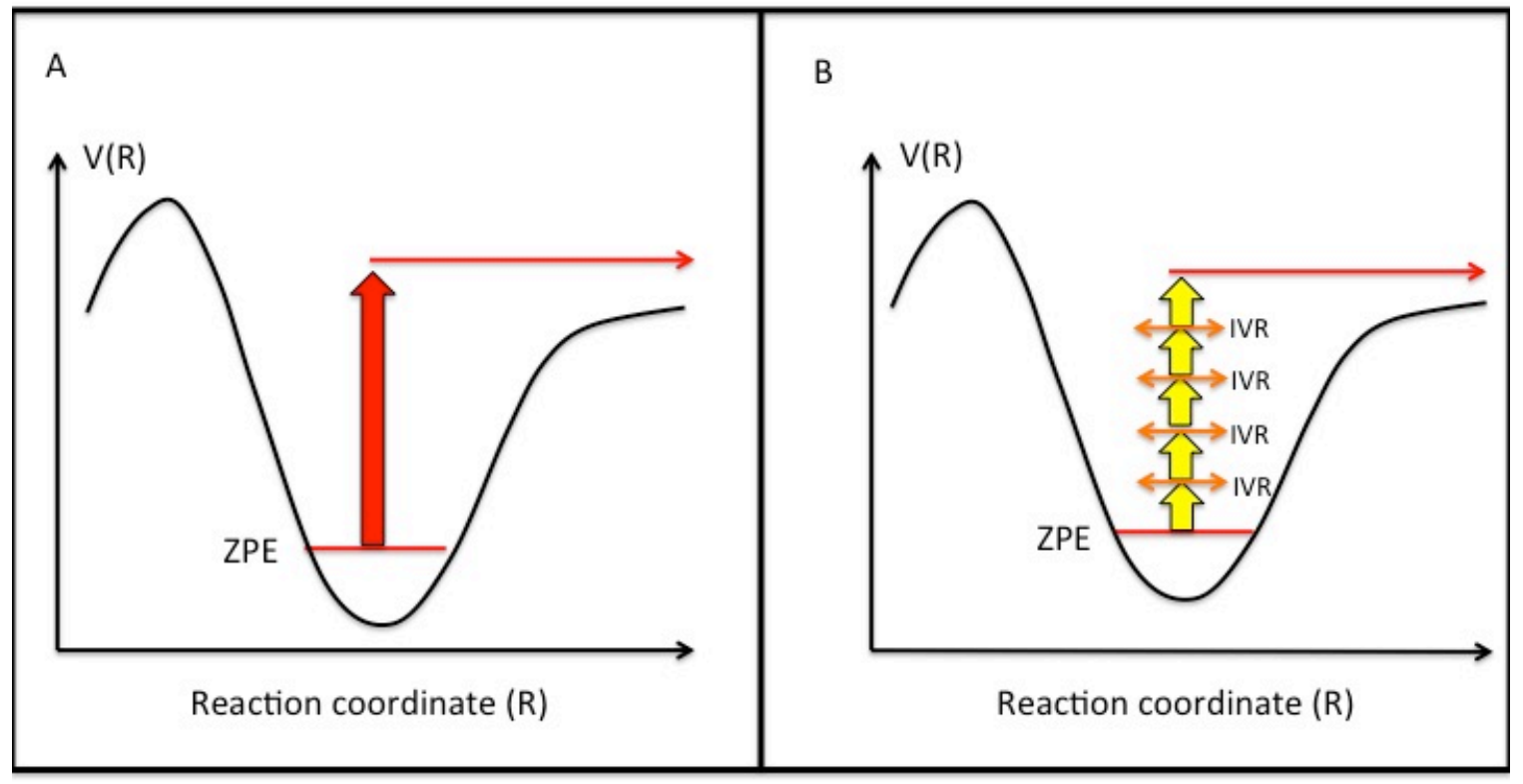

Figure 8. 
For Table of Contents Use Only

Role of Chemical Dynamics Simulations in Mass Spectrometry Studies of CollisionInduced Dissociation and Collisions of Biological Ions with Organic Surfaces

Ana Martin Somer, Veronica Macaluso, George L. Barnes, Li Yang, Subha Pratihar, Kihyung Song, William L. Hase, and Riccardo Spezia

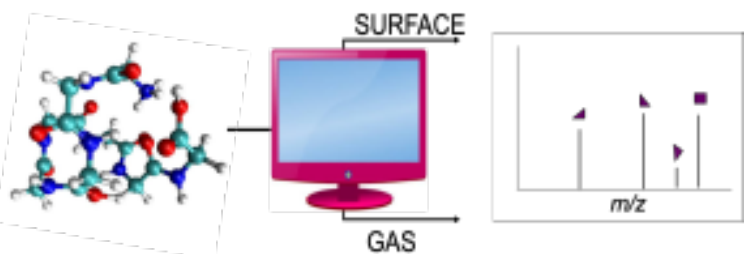

Starting from an initial structure of a biological ion, computer simulations can provide fragmentation products as in CID and SID experiments 